\title{
From decision theory to decision aiding methodology
}

\author{
Alexis Tsoukiàs \\ LAMSADE - CNRS, Université Paris Dauphine \\ tsoukias@lamsade.dauphine.fr
}

\begin{abstract}
The paper presents the author's partial and personal historical reconstruction of how decision theory is evolving to a decision aiding methodology. The presentation shows mainly how "alternative" approaches to classic decision theory evolved. In the paper it is claimed that all such decision "theories" share a common methodological feature, which is the use of formal and abstract languages as well as of a model of rationality. Different decision aiding approaches can thus be defined, depending on the origin of the model of rationality used in the decision aiding process. The concept of decision aiding process is then introduced and analysed. The paper's ultimate claim is that all such decision aiding approaches can be seen as part of a decision aiding methodology.
\end{abstract}

Keywords: History of OR, Methodology, Decision Aiding Process 


\section{Introduction}

Quite often I get asked what my job is. When I reply that I work in decision aiding, people remain perplexed and quite often ask "aiding what decisions?".

Indeed decision making is an activity that every person does every day. We all make decisions constantly, from the simplest "should I take my umbrella" ([241]) to the more complex "how should the international disarmament treaty be applied?" ([160]) and at all levels, individual: ("should I divorce?" [327]), organisational ("how do we schedule the crew shifts?" [59]), inter-organisational ("which trace for the highway?" [231]). Quite often, during such decision processes we ask for help, advice, or support from friends, experts, consulting companies etc.. Several questions arise. Is it conceivable that a decision aiding methodology could exist independently from any specific domain, one which could be used in all such situations? Can an expert in decision aiding exist who is not an expert in any particular domain? What would be the difference between such an expert and a psychotherapist, a physician, a lawyer, an expert in logistics or your best friend?

What characterises decision aiding, both from a scientific and a professional point of view, is the fact that is both "formal" and "abstract". By the first term I mean the use of formal languages, ones which reduce the ambiguity of human communication. By the second term I mean the use of languages that are independent from a specific domain of discourse. The basic idea is that the use of such languages implies the adoption of a model of "rationality" a key concept in decision aiding. Does it make sense to use such a language always and in any context? Obviously not. Being abstract and formal presents several disadvantages:

- it is much less effective with respect to human communication;

- it has a cost (not necessarily monetary);

- reducing ambiguity might not be desirable;

- it imposes a limiting framework on people's intuition and creativity.

Nevertheless, there are also presents several advantages, which in some circumstances can be interesting (see also [45]):

- it allows the participants in a decision process to talk the same language, a fact that improves transparency of the process and possibly increases participation (for an example see [15]);

- it allows the identification of the underlying structure of a decision problem (if there is any) and therefore allows the re-use of procedures and models (for nice examples see any textbook of Operational Research, for instance [336]);

- it is not affected by the biases of human reasoning that are due to education or tradition (for examples the reader is referred to [248]);

- it may help to avoid the common errors that are due to an informal use of formal methods; a typical case being the use of averages as a universal grading procedure 
(see [45] for a critical discussion of this issue).

In general terms, a formal and abstract language allows us to better analyse, understand, explain, justify a problem and/or a solution. It should be noted that organisations, companies, institutions, entreprises, ourselves, ask for and use formal methods of decision aiding. Students are promoted using the average of their grades. Traffic restrictions are applied based on a pollution index. Credit demands are rejected because of the client's credit rating. Production is scheduled, highways are designed, networks are administrated, using formal methods of decision support. In reality decision aiding is present in many aspects of our everyday life. People do not necessarily use this term, but there is always a formal and abstract language which is used in all the above examples. Therefore, when I talk about decision aiding I will always mean the use of a formal and abstract language in order to handle problem situations faced by individuals and/or organisations.

In this paper I will first present a brief history of the evolution of this domain from a scientific and a professional point of view (next section). Such a historical reconstruction pretends neither to be complete nor rigorously organised. Several readers might feel disappointed that some very important scientific achievements are not recognised. Indeed this is an essay which reflects my very personal point of view and is biased by at least three factors:

- scientific; I am not an expert in all areas of decision theory and operational research and I tend to emphasise in my presentation what I know better;

- professional; the real world experiences of decision aiding that I had the opportunity to conduct do not cover all different aspects of practicing decision aiding, so that I have a partial vision of this complex reality;

- geographical; being an european (western) I have not been exposed to the bulk of the contributions produced in decision theory and operational research just behind the corner (see for instance [181], [174]) and this is a severe limitation.

In section 3, I will present and discuss different decision aiding approaches that have been introduced during the 60 years of existence of this discipline: normative, descriptive, prescriptive and constructive approaches. I will try to explain the differences among these approaches by examining the origin of their particular "models of rationality". In section 4, I will place myself within a constructive decision aiding approach and I will discuss how a decision aiding process is structured. In order to do that I will examine the "artifacts" produced by such a process: the representation of a problem situation, the definition of a problem formulation, the construction of an evaluation model and the formulation of a final recommendation. Such a presentation will allow me to differentiate decision aiding from other areas of scientific investigation such as automatic decision making.

The ultimate message I wish to deliver with this essay is that decision aiding is a human activity that can be (and actually has been) the subject of scientific investi- 
gation. Different "decision theories" have been developed with specific characteristics. At the same time different "decision aiding practices" have been developed either as a result of testing theoretical conjectures or as a result of aiding real decision makers (individuals, organisation or collective entities) in their work. There is no one-to-one correspondence between "theories" and "practices". Nevertheless, I consider that all such "theories" and "practices" define a whole which I will call "decision aiding methodology". The reader should note that in the text I use the term "methodology" in a very precise way: reasoning about methods. I claim that we have several methods, but we should establish a common methodology for decision aiding purposes. Such reflections are discussed in the conclusions section. At the end of the paper I provide a long, but definitely partial list of references, an exhaustive presentation of the literature being impossible.

\section{Some history}

\subsection{Genesis and youth}

We can fix the "origin" of decision aiding as starting sometime just before the second world war, in the studies conducted by the British army on their new radar system installation and their efforts to break the German secret communication code (1936-37). The reader can get a flavour of this period in [53], [175]. It is the first time the term "operational research" (in the USA "operations research") appears. The problem of how decisions are or ought to be taken by individuals, organisations and institutions was previously discussed by Aristotle ([11]) and more recently, during the 18th century (see [32] on probability, [105] on combinatorial problems, [38], [72] on voting and social choice procedures) and also at the beginning of the 20th century ([234] on economic problems under multiple dimensions, [107], [297] on the scientific management of enterprises, [81], [82], [177], [245] on probability theory, [303] on decidability). In all these contributions the concept of decision is central. I may just mention that, in order to argue for their thesis that probability only exists in terms of subjective belief, both Ramsey and de Finetti, have used what today is known as comparison of lotteries and the associated preferences of a decision maker. "If the option of $\alpha$ for certain is indifferent with that of $\beta$ if $p$ is true and $\gamma$ if $p$ is false, we can define the subject's degree of belief in $p$ as the ratio of the difference between $\alpha$ and $\gamma$ to that between $\beta$ and $\gamma$. This amounts roughly to defining the degree of belief in $p$ by the odds at which the subject could bet on $p$, the bet being conducted in terms of differences of values as defined" ([245], p. 179-180).

In any case, it is the undeniable success of operational research in supporting military and intelligence activities of the allies that grounded the idea that decision 
making (and I extend to decision aiding) can be studied using a scientific approach and that general models of decision support were possible. Towards the end of the $40 \mathrm{~s}$, beginning of the $50 \mathrm{~s}$, several fundamental contributions appeared: (see [78], [166] for linear programming, [218], [219], [320] for decision and game theory, [304] on algorithmics and the definition of "machines" able to solve "any problem"). It is during that period that the first scientific societies of operational research (in the United Kingdom in 1948, in the United States in 1950) and the first scientific journals appeared ([34]). Also the first real world applications of this new discipline (in non military applications) appeared (see [79]) as well as the first companies specialising in "decision aiding" (but this term was not used at that time). The best known example is the RAND corporation. Within RAND, operational research was developed into a "science" to be applied to the multiple problems of the new post-war industrialisation.

Such first contributions and experiences were characterised by the search for formal structures underlying precise decision problems and the use of mathematics and logic as modelling language. For an interesting presentation of the origins of these contributions as have been perceived by their authors themselves, see [193]. The first steps in this direction strengthened the idea that complex decision problems can be modelled through the use of a simple rationality model (maximise an utility function of the decision maker's decision variables, a function which is expected to faithfully represent the decision maker's preferences). Von Neumann and Morgenstern and Nash contributions showed under what conditions such functions exist. Further on, the linear programming algorithm developed by Dantzig (the famous Simplex algorithm) introduced the first tools by which such problems could be effectively solved (even for large dimensions). Turing and also Wiener ([335]) and Ashby ([13]) went further to consider the possibility of formulating a general theory of computation and conceived "general problem solver" machines.

At that time, some critical contributions to this paradigm started to appear (although they were not always conceived as criticism). In 1951 Arrow ([12]) published his famous impossibility theorem, showing that aggregating the preferences of rational individuals, under conditions considered natural (universality, independence, respect of unanimity, non dictatorship), is impossible (if the result has to be "rational", that is a complete order). Arrow's result closed the discussion opened by Borda and Condorcet (in the sense that we know there is no universal preference aggregation procedure, [43], [317], [318]). At the same time it paved the way to the huge literature on social choice theory (the reader can see: [172], [173], [226], [227], [273], [275], [296]).

In 1953, Allais ([8]) published his famous paradox, where he showed that the axioms, introduced by von Neumann and Morgenstern as necessary and sufficient conditions for the existence of an utility function (and implicitly assumed necessary 
in order to exhibit a rational behaviour), are systematically violated in the behaviour of real decision makers when they are confronted by very simple choices (the reader can also see [74], [205]). Such an empirical falsification of the expected utility theory opened another research direction on integrating the findings of cognitive science into decision theory (see for instance [9]).

Already in 1947, Simon ([279]) observed decision processes occurring within real organisations and concluded that the behaviour of real decision makers is far from the postulates of decision theory, at least as this theory was formulated at that time. During the 50s, Simon ([280], [281], [282]) developed his "bounded rationality" theory, which states that a decision maker facing a choice behaves on the basis of a local satisfaction criterion, in the sense that he will choose the first solution which he subjectively considers as satisfactory without trying to attain an unrealistic (and useless) optimal solution. Actually Simon considers decision theory to be based on three implicit hypotheses (see the discussion in [216]):

- decision makers always know their problems well;

- such problems can always be formulated as an effectiveness (or efficiency) problem;

- the information and the ressources necessary to find a solution are always available.

None of these hypotheses is true in reality (following Simon):

- decision makers never have a very precise idea of their problem;

- often their problems can be formulated as the search for a "satisfying compromise";

- solving a problem is always constrained by the available resources and time.

The innovation introduced by Simon is radical. Decision theory as had been developed up to that moment always considered the rationality model as existing independently from the decision maker and his decision process. Simon put at the center of his reflection the decision process (the mental activities of a decision maker) and postulated that a rationality model has to be found within such a process and not outside of it. The problem with this hypothesis is that, while an "exogenous rationality model" is compatible with an optimisation model (indeed the classic rationality model is based on optimisation), this is not always the case with a subjectively established model (at least not automatically or necessarily). Simon's work opened several research directions, both towards the creation of new decision aiding approaches (see for instance [189]) and towards what today is known as "artificial intelligence" (see [283]). It should be noted that the idea of looking for a satisfying solution has an immediate application to the problem of finding an acceptable compromise when the decision is subject to the presence of multiple criteria (see [319]).

At the end of the 50s, beginning of the 60s, several "classic books" appeared. 
These books were used to train generations of researchers and practitioners ([31], [60], [68], [73], [80], [106], [115], [124], [150], [199], [313]).

The 50s and the 60s saw significant increases in research, university classes and applications in different domains. Typical big clients of such studies were the companies managing networks (water distribution, telecommunications, electricity suppliers, railways, airlines). In addition, several consulting companies, specialising in operational research and decision support appeared. It should be remembered that these years were the ones where the world was trying to reconstruct itself after the war and tremendous resources were invested in trying to find viable and efficient solutions to important industrial and economic problems. Unsurprisingly there have been stories of success and failure. Such experiences allowed the first critical approaches to the now well established "classic" decision theory to become stronger (for early discussions see [3], [6], [67], [75], [178]).

At the beginning of the 60s, Zadeh published his famous paper ([337]) about fuzzy sets. The paper introduced a new perspective on the treatment of uncertainty, ambiguity and linguistic variables. Zadeh's innovation had a major impact on the future of the discipline, since it concerns a fundamental aspect of formal languages: set theory. The extension of set theory through the introduction of a "membership function", a "measure" of an element's membership to a given set, allowed the increase of both the expressivity and the flexibility of formal languages and therefore of the decision aiding models using them.

Another domain which introduced major contributions to the development of alternative approaches to decision theory is cognitive science and psychology (see [101], [108], [194], [195], [277], [288]). Allais' intuition to experimentally validate the axioms of decision theory was followed by several researchers. I just quote here the work done by Tversky (see [305], [306], [308]). He showed that the properties, intuitively considered as rational for preference relations, are more a theoretical imposition, not necessarily corresponding to the behaviour of real decision makers. Tversky showed that preference can well be intransitive ([306]) and that similarity can be non symmetric ([308]).

Such results emphasised the necessity of pursuing a more thorough study of the fundamental structures on which decision aiding models rely, namely the structure of preference relations ([97], [197], [272]) and of the functions which represent them (value or utility functions, see [110], [179]). For further work on this subject the reader can see [112], [240], [249], [253] (see also the recent survey [232]).

Remaining within the influence of the psychological studies, it should be observed that during the 60s appeared a psychotherapy movement known as "relational psychotherapy" based on an approach claimed by the authors to be "con- 
structive" (see [22], [137], [328]). Within such an approach, the importance of how a problem is formulated was emphasised as well as the importance of the relationship between the one who asks for help and the one who provides such help (the patient and the therapist in their terminology). This approach also emphasised the fact that a problem is not something given within a decision process: the process of defining and solving a problem is the same. Under such a perspective the solution of a problem is a construction and not the result of a search in a space of solutions nor a classic inference from a set of sentences (see the classical dichotomy in artificial intelligence literature, [286]).

Let's remain in the 60s and the first organisational studies concerning the behaviour of decision makers and the structuring of decision processes within real complex organisations. It was again Simon who gave a significant impulse to the research in this direction (see [76], [103], [204]). In these works, it was shown that the behaviour of an organisation (supposed to be composed by rational decision makers) does not correspond to the rational behaviour as described by decision theory (the reader can see an extreme model in [71]: the famous model where organisations are seen as garbage cans). The problem, already observed by Weber ([331]) in his studies during the 20s on the bureaucracies, is that within an organisation different forms of rationality may co-exist (see [284]). Later on, related research was condensed in Mintzberg's work (see [209], [210], [211], also [207]).

During the 60s the concept of "decision" and "value" was the focus of interesting research in philosophy which posed the question: is it possible to define the concept of "good" in a formal way? Von Wright ([322], see also [144]), published his "Logic of Preference" within which the sentence " $x$ is preferred to $y$ " is considered true if all the worlds where $x$ is true are preferred to the worlds where $y$ is true. This research direction was followed by [65], [66], [145], [146], [159] and by the work done in [246], [247]. Von Wright continued in ([323]) (see also Huber in [152]). From this research direction was further developed what today is known as deontic logic (see [151] and more recently [1] and [228], for a criticism see [217]).

Coming back to more formal aspects of operational research and decision aiding it should be noted that during the $60 \mathrm{~s}$, the first works concerning algorithmic complexity appeared. Hartmanis and Stearns ([148]) were the first to pose the problem in the form we know it today. On this basis Karp ([167]) proposed the classification currently in use. This gave the formal basis used by Garey and Johnson ([123]) in order to compile their famous "encyclopedia" (see also [233]). This research opened a big issue in optimisation. Several algorithms used to solve classic operational research problems (and others) appeared to be less useful in practice, since, in presence of large instances of the problem, the resources required to reach an optimal solution are immense and independent of the computer used. We just mention the problem of satisfying a logical clause and the famous "travelling 
salesman problem" (see [113], [215] and moreover [196] which introduced one of the most widely used algorithm in combinatorial optimisation: Branch and Bound; for a survey see [188]). Looking for an optimal solution, besides its cognitive, theoretical and epistemological problems, became also a practical problem.

The research program of artificial intelligence (see for example [224]), oriented towards the creation of "thinking machines" and the establishment of "general problem solving" procedures was boosted by the work of Newell and Simon ([222], [223]). The idea of looking for a satisfying solution (instead of an optimal one) was a partial reply to the problem of the resources required to arrive at a conclusion for any decision process. The question was re-formulated under a more "logical" approach by McCarthy and Hayes (see [206]), who opened the way to what today is known as non-monotonic reasoning and by Minsky ([208]) who suggested the use of new techniques to represent "knowledge", the latter being seen as the source of efficient problem solving.

Finally, during the 60s, appear the first works on the problem of evaluating alternative decisions using multiple criteria, where the criteria could be conflicting. In reality this is the case in most decision situations. It was the choice (and sometimes the necessity) of researchers and of practitioners that pushed them to simplify problems using a single decision criterion. In 1955 Charnes et al. proposed the idea of "Goal Programming" ([61]). This work was further developed in [60] opening the way to what today is known as "multi-objective programming" (for the first papers see [29], [127], [128], [277], [339]). Bernard Roy presented his ideas on this issue for the first time in 1966 and then in 1968 ([30], [254]) opening the way to an approach known as "outranking based" methods. Raiffa produced his famous RAND report on these types of problems in 1969 ([244]). In 1972 the first international conference in this domain (see [69]) took place and in 1976 Keeney and Raiffa published their reference book ([171]) extending utility theory (see [110]) in the presence of multiple criteria.

The presence of multiple criteria poses a fundamental question. The concept of "vector optimum" makes little sense from a mathematical point of view (at least in the natural terms of minimising the value of a function). The only "objective" definition that can be introduced is the one of "efficient solution ([234]). A solution is considered efficient if there are no other solutions at least as good as the current one and strictly better under at least one criterion (dominance). The problem is that the set of efficient solutions can be extremely large and therefore useless from a practical point of view. Technically the different approaches can be distinguished by the procedure used to explore the set of efficient solutions in order to find the "better compromise" (again a concept with no precise mathematical definition). On the one hand we have approaches based on the establishing of a function that aggregates the different criteria in a single criterion (a multi-attribute utility func- 
tion), the problem thus becoming again an optimisation one. On the other hand we have approaches based on the idea that the criteria can be seen as individuals having preferences and to use methods originating in social theory (for instance voting procedures) in order to obtain a global preference relation representing the whole set of criteria, where graph theory is used to obtain a final solution (since such comprehensive preference relation can be seen as a graph).

I will give some more details later on in this historical section about the differences among these two approaches. However, it should be noted that it quickly appeared that there were deeper differences than just the technical ones. These concerned how decision aiding is conceived and implemented rather than the technical procedures and the use of a specific method (for an interesting discussion on this issue see [259]). I will discuss such issues in section 3.

I will conclude this first part of the history noting that at, the end of the $60 \mathrm{~s}$, beginning of the 70s, operational research and decision theory were having a period of strong development both in theory and in practice. This development together with the establishment of a dominant paradigm allowed the appearance of critical approaches which occupied the scene during the period I will call the "maturity period". It is interesting to note that:

- the discussion about alternative "decision theories" has been rooted into practical problems; it is the quest for better helping real decision makers involved in real decision processes that pushed the research to explore "innovative" or "alternative" approaches within the discipline;

- the development of OR and Decision Theory created "branches" (such as game theory, mathematical programming, decision analysis etc. just to give some examples) which started having their own independent evolution.

\subsection{Maturity}

In the following of this partial reconstruction of the evolution of decision theory I will focus on some research directions that I briefly introduced in the previous part. As emphasised previously, the entrance of decision aiding into "maturity" ([47]) implied the establishment of different "branches", a specialisation that I will observe under the following directions:

- the structuring and formulation of decision problems;

- the contribution of cognitive sciences;

- the intersection of artificial intelligence and decision theory;

- the treatment of uncertainty;

- the development of multiple criteria decision analysis;

Such directions have been followed either within the OR and decision theory communities or by researchers coming from other fields sharing with OR an interest 
towards the concept of decision support. I will try to show that these directions do not diverge, but rather that they have several common points and potential areas of convergence.

As in other empirical sciences, operational research and decision theory entered their first official "crisis" for a practical reason. Towards the end of the 60s, the British OR society wanted to create a kind of "chartered directory of OR professionals". The reason was simple: provide the practitioners of the domain a quality label allowing the discipline and its practice to be better promoted. Not surprisingly ORSA (in the USA) published, almost at the same time, its suggestion about the "the guidelines of OR practice" (see[229]). The initiative was followed by several questions: what are the boundaries of the "discipline" and how to fix them? Using the existing methods? Who decides whether a decision support method belongs to the discipline? Given a new method, how will it be legitimated to enter these boundaries? The difficulty in finding convincing answers to these questions let appear the differences between diverse decision theories and their critics. For the history, this debate reached a conclusion(?) only very recently (the British society finally modified its statutes in order to create the above mentioned directory in 2001!!!).

The reader can get an idea of this discussion in the famous articles of Ackoff ([4], [5]). A reconstruction of this discussion is also available in the introduction of [251]. An interesting perspective on the discussion about the "operational research crisis" is also in [44].

During the 70s (mainly in the United Kingdom) there appeared new approaches to decision aiding, based on work done within the Tavistock Institute ([104], [119], [293], [298]) and by Stafford Beer ([23], [24], [25]). The reader can see a presentation of such approaches in [251]. I just quote here the better known: "Soft Systems Methodology", [63], "Strategic Choice", [118], [119], "Cognitive Mapping", [99], [100], "Robustness Analysis", [250], [252].

Let's recall that in classic decision theory a decision problem is formulated in a unique way. It is always a problem of maximising a function on the outcomes of all potential actions. There is no alternative to this formulation and the decision maker has to adapt the information available and the perception he has of the problem to the axioms of the theory. In contrast, the new approaches claimed that the most important part within a decision aiding process is the one concerning the structuring and formulation of the decision problem. This practice was already being followed in certain psychotherapy methodologies [329]). Within such new approaches the attention is focussed on the interactions between the client(s) and the analyst(s). Several techniques were proposed in order to arrive at a definition of a representa- 
tion of the problem situation on which all the participants could agree (see also the work done in [18], [182], [183], [216]). What these approaches suggest is that once the decision makers have understood their problem, solving it is a secondary issue and in most cases a simple one. Little attention is indeed paid to how the problem can be formulated in logical/mathematical terms (this aspect has been criticised on several occasions). However, it cannot be denied that structuring and formulating a problem remains one of the most critical parts within a decision aiding process as several real world experiences have shown (see [16], [27], [64], [251], [291]). I will go to discuss this issue in more detail in section 4 .

As I have already mentioned in the previous part, decision theory has also been criticised on a cognitive basis. Several experiences (conducted mainly in the laboratory) have shown that decision makers do not behave as decision theory axioms pretend. Such experiences have also shown that the frame within which and the precise way a decision problem is formulated have a great influence on the behaviour of the decision maker. For instance asking for preferences between two alternatives presented in terms of gains or losses gives totally different answers. More generally the cognitive context of the decision process is fundamental for the final result. For the first experiments conducted in this direction the reader can see [165], [310], [311].

A first tentative reply to these theoretical and practical problems was the extension of utility theory through the introduction of "belief coefficients" which were expected to take into account the cognitive context. The theory is now known as "prospect theory" ([165]). Although the complete axiomatisation of this theory is still to be done (see for instance [325]), it has been the subject of a large research area that is still extremely active today ([35], [62], [132], [162], [163], [168], [198], [200], [287], [321], [326]).

Another tentative answer developed at the same time (not necessarily in opposition to the previous one) had as an objective to identify "decision strategies", the procedures used by decision makers when facing a problem situation. One of the first to observe such behaviours was Tversky ([307]). Similar type of studies can also be found in [21], [213], [214], [129]. The common pattern of this research is always the same: the identification of regularities in the behaviour of the decision makers, such as the progressive elimination of alternatives or the research for dominance structures. The reader can see reviews of this approach in [294] and in [20]. What such approaches basically contributed was the centering of decision aiding on the decision maker, his cognitive effort and the decision context. For the first time decision aiding was focussed on the decision process and not on the decision theory. 
The reader will recognise in the previous approach some of Simon's cognitive criticism. Simon's contribution found a fertile area of expansion in Artificial Intelligence. One of the principal points of view of Simon was that decision theory payed (at that time) little attention to the "process" of problem solving and the necessary resources. In Simon's mind Artificial Intelligence could fil this gap. Indeed large part of the research conducted in this area concerned (and concerns) well known decision problems. It is interesting therefore to observe how these two research areas evolved.

One common area of interest between artificial intelligence and operational research concerned optimisation and planning algorithms with mutual benefits for both research areas. Indeed the problem of establishing a plan in order to "solve a problem" has been often viewed in artificial intelligence as the exploration of a tree structure where the nodes represent "states of the world" and the arcs represent transitions from one state to another ([109], [225], [263]). The goal of such an exploration is to establish a path from a state of the world which represents the present situation and a state of the world which represents the solution. Such an exploration is mostly based on the estimation of the length of the path remaining in order to reach the state of the world desired (the solution), as can be seen in the famous $\mathrm{A}^{*}$ algorithm ([147]). Indeed the state space tree has a structure similar to the one generated by a Branch and Bound algorithm and it is explored using similar principles. In doing that, AI researchers used and use concepts derived from integer and dynamic programming methods developed in OR (see for instance [37] [42]). At the same time AI researchers developed the so called "constraint satisfaction" based methods (see [299], [314]). Such methods have been largely applied in typical operational research problems (see [10],[19],[36], [58],[94]). Practically the two communities were sharing (and still do share) a common concern: solve efficiently problems which are or can be considered decision problems. From this point of view the development of heuristics for the solution of hard optimisation problems common to both communities should be noted (see [2], [135], [136], [138], [239]). A partial bibliography on the above issues can be seen in [158].

Another interesting interaction was developed around what today is known as "qualitative decision theory". The issue here is to extend decision theory through the use of symbolic approaches not requiring the imposition of further hypothesis in order to quantify information (see [39], [40], [41], [55], [56], [57], [89], [90], [92], [96], [190], [191], [295], [332]). The problem is how to formulate a theory where the preferences are simply order relations and uncertainty is purely qualitative. The reader can see an exhaustive presentation and discussion of this issue in [93]. The result is that, if we want to remain within the frame of Savage's axioms, such a theory is too weak. Indeed as pointed in [93] the decision rules obtained within such an approach are either not decisive or overconfident, thus not interest- 
ing from an operational point of view. The reasons for such a "negative result" are related to the impossibility results present in social choice theory (the resulting decision rule is likely dominance).

Last, but not least, a field of interesting research has been established in "preferential entailment". Doyle, [85], and Shoham, [278], have observed that a reasoning system with only simple inferencing capabilities was not able to take into account preferences which are considered a fundamental element of human capability to solve problems. Their suggestion was to enhance inference systems, namely the ones able to perform non monotonic reasoning, with an ordering relation among the possible interpretations of a logical clause in order to obtain "preferred" consequences instead of only "true" ones. Such an idea has been followed by several other researchers (under different perspectives: [7], [54], [86], [87], [88], [120], [121], [180], [192]). Nevertheless, once more, as Doyle and Wellman have shown [91] (see also [93]), the problem of aggregating such orders remains within the frame of Arrow's impossibility theorem.

Such results may appear. However, they also open interesting research perspectives, such as relaxing the axiomatic frame within which to look for a solution (see for instance [333] or exploring the so called "non rationalisable" choice functions; see [274],[276]).

Another major innovation within the frame of decision theory has been the introduction of fuzzy sets and more particularly of possibility theory (see [95], [338]). In order to get a general view of how these formalisms contributed to decision theory the reader can see two more reference books on this subject ([114], [289]).

I will focus my attention on two specific contributions.

- The consideration of preference relations as fuzzy subsets (see [114], [161]). This allowed to relate such concepts to the already existing literature on valued binary relations and graphs (see for instance [84]). The use of fuzzy sets theory has thus been extended to other decision aiding concepts: choice sets, kernels etc. (see [33], [176]). The reader can see chapters 1 and 2 in [289] and for a recent review [232]. - The development of new aggregation procedures. Aggregating "uncertainty measures" or "fuzzy measures" is similar to aggregating preferences (see [237] and chapter 7 in [45]). As a consequence it has been developed a literature on the use of new aggregation operators (mainly based on the use of fuzzy integrals: [140], [141].

More generally speaking, possibility theory introduced the use of formalisms for representing uncertainty different from probability. The motivation for that was the consideration that the additive property of probability was problematic and 
the consequent conceptual discussion when subjective estimation of uncertainty is considered (see for example [221]). The ordinal nature of possibility distributions allowed their use in a more flexible way for several different domains of decision aiding (see for instance [265], [266], [290]) although did not solve all conceptual problems (where numerical estimations come from?). That said the reader should remind that since the late 80 s there has been a large discussion on innovating the whole field of decision under uncertainty and risk: see [70], [130], [131], [133], [134], [156], [157], [155], [201], [202], [203], [220], [271], [243].

I will conclude the discussion on handling uncertainty by recalling the contributions based on the use of other logic formalisms that allow the inevitable uncertainties, ambiguities and inconsistencies which characterise a decision aiding process to be taken into account (see [116], [238], [300], [301], [302]).

In the first part of this historical reconstruction, I have argued that the formulation of a decision problem as an optimisation one is a simplification of reality. Decision problems are almost always situations where we find several different dimensions, several points of view, several participating actors and stakeholders, each of them carrying within the decision process his values, his preferences and his criteria. The optimisation simplification does not always allow to consider the complexity of the decision process.

Remember that, from a technical point of view, multiple criteria decision aiding methods can be grouped in two categories, based on how the set of the potential alternatives is explored:

1. the establishment of an utility function synthesising the different criteria;

2. the use of pairwise comparison procedures and majority principles for establishing a final recommendation.

Within the first category we find methods based on the construction of a multiattribute utility function (see [171]) and the methods which interactively explore the set of efficient solutions of a multi-objective program (see [122],[316]). Possibly specific heuristics apply to these types of problems (particularly in the case of difficult ones such as in combinatorial optimisation, see [312]). The reader can see an excellent reference survey in [102]. The construction of the utility function can be obtained either directly (see for instance [321]) or indirectly (through for instance the AHP method, [264], the UTA method, [154] or the MACBETH method, [17]).

Within the second category we find the methods known as "outranking methods". This name was given by Bernard Roy ([255]) to the preference relation representing the concept "at least as good as". Such methods are based on the principle: when we compare $x$ to $y$ under multiple criteria, $x$ will be at least as 
good as $y$ if it is the case for a weighted majority of criteria and there are no strong "blocking minorities" (for a discussion see [301]). The reader can get more details on these methods in [257], [261], [269], [270], [319]. Recently the possibility of constructing such a relation from holistic evaluations of the alternatives, provided by the decision maker, was shown in ([142], [236]).

Such different methods each present advantages and disadvantages. The construction of an utility function is more restrictive (in the sense of the conditions to be fulfilled) and requires a considerable cognitive effort on the part of the decision maker (not necessarily intuitive). On the other hand it allows to obtain a rich result and is axiomatically well founded. The "outranking methods" are much more flexible (since there are less conditions to respect), but they risk obtaining a very poor result and are sometimes difficult to justify from an axiomatic point of view. The reader can see an interesting discussion on this issue in [28] and in chapter 6 in [45] as well as in chapters 4, 5 and 6 of [46].

However, the separation in categories of the above methods can be misleading. Adopting a conjoint measurement point of view Bouyssou and Pirlot (see [48], [49], [50], [51], [52]) have shown that is possible to give a common axiomatisation to all such methods. Moreover, authors coming from different backgrounds (see [28], [77], [117], [139], [169], [170], [256], [258], [259], [260], [292]) have often claimed that if any differences exist among the methods these depend in reality more on how the decision aiding process is implemented and less on the specific method adopted.

Concluding this historical reconstruction I may summarise my claims as follows.

- Despite the specialisation of the last years Operational Research and Decision Theory can be still viewed as a unique "discipline" (as its founders did more than 60 years ago).

- OR and Decision Theory are deeply rooted in practicing decision support, aiding real decision makers in real problem situations, involved in real decision processes. Even the more abstract theoretical results have originated by precise practical problems and the research for models fitting real demands. Theoretical soundness has always been accompanied by empirical validation.

- The evolution of the discipline has been influenced certainly by the vitality of the research conducted within it, but it has greatly benefit from "cultural contamination" from other disciplines such as philosophy, psychology, 
organisation theory, political science, logic, mathematics and computer science.

- There is an increasing interest at issues such as how to structure and formulate a problem, how to conduct and implement a decision aiding process, how to handle the relations with the client of the decision support requested, how to train young people to undergo the profession of OR and/or Decision Analyst. The issue here is to go one step further the development of "decision theories" (which are in excellent shape) towards what I call a "decision aiding methodology": a body of knowledge and a coherent structure of reasoning about theories and practices concerning deciding and aiding to decide. Within such a methodology it is possible to distinguish different approaches and in the following section I will try to sketch their principal differences.

\section{Different decision aiding approaches}

In order to be able to help someone to make a decision we must be able to elaborate his preferences. Indeed what we know are his "problems" and his "desires" (the problem situation). What I am talking about here is an elaboration based on the use of a formal language. Moving from the problem situation to a decision aiding model and the actions such a model might imply requires the use of what I call a "model of rationality", a tool enabling the translation of "informal" information (which is also naturally ambiguous) to a formal representation (where even ambiguity is represented in an unambiguous way). The question is where this model of rationality comes from.

I am going to support my presentation through an example. In the following I will use the term "client" to represent the person or collective entity that asks for decision support. The client is potentially, but not necessarily, a decision maker. Consider a client with a health problem who has a number of diagnoses and a certain number of proposed treatments. Assume that there is some uncertainty associated to the diagnoses and therefore to the outcomes of the treatments. What do we suggest to this client to do?

The classic approach in decision theory is straightforward. To each diagnosis (the states of the nature) is associated a probability and to each treatment (the potential actions) the respective outcomes. Using any of the standard protocols for constructing the client's value function on the set of the outcomes we are able to define an utility function (including uncertainty), which, when maximised, identifies the solution which should be adopted (since by definition, it is the one which 
maximises the client's expected utility). The existence of such a function is guaranteed by a certain umber of axioms that represent what, following the theory, should be the principles of a rational decision maker's behaviour ([267]). Preferences are supposed to be transitive (and complete), since the presence of cycles would imply that the decision maker will be ready to infinitely increase what he is ready to pay for any of the solutions and this is considered inconsistent with the idea of rationality. Similarly preferences about uncertain outcomes ought to be independent from probabilities ${ }^{1}$ (thus allowing to construct a mathematical expectation). It should be noted that there has been no observation of the client behaviour nor it has been posed the question of what other decision makers do in similar situations. It is the decision maker who has to adapt himself and his behaviour to the axioms. Otherwise he is not rational and the information and his preferences ought to be modified. This type of approach is usually called normative.

It should be noted that although the model handles uncertainty, there is no uncertainty at all associated to the model itself: the diagnoses are all the possible diagnoses and the treatments also. The only issue is to find the best choice for the client. As with laws or ethical norms the legitimation of the model of rationality is external to the problem situation. The model of rationality is a law of behaviour imported into the decision process. The reader can see several classics on this approach such as: [110], [111], [199], [267], [324]. For a nice discussion on how "rational" such an approach is, the reader can see [212].

However, it might be the case that the client's behaviour does not respect the axioms of the classic decision theory. Aa an alternative one could look for a model of rationality based on empirical legitimation instead on a theoretical one: if other decision makers followed a certain strategy in order to make a decision under similar circumstances, why not apply the same to the present one? This is the basic idea of the approach usually call descriptive: define models and decision strategies based on the observation of real decision makers (see [153], [164], [242], [321]).

Once again it should be noted that we impose a model of rationality which is independent of the problem situation. Nevertheless, there are more degrees of freedom. The client's personality is considered as a source of information. The problem is not necessarily formulated as an optimisation one (several alternatives are possible). On the other hand, as for the normative approach, we are sure about the problem and the model: we are looking for the best treatment for the client given the diagnoses, the treatments and the uncertainties of the outcomes. I might recall that some of these ideas can be found at the origin of the research on expert systems (see the nice discussion in [149]).

\footnotetext{
${ }^{1} P \succ Q, \quad 0<\alpha<1 \Rightarrow \alpha P+(1-\alpha) R \succ \alpha Q+(1-\alpha) R$, see [110], page 107.
} 
The problem is that we can find ourselves in a situation where the client cannot be associated with any model of rationality more or less ready made. He might exhibit intransitive and/or incomplete preferences. His perception of the uncertainty might escape any effort to quantify or to measure it. Moreover, the client might be aware that he has to "improve" the structure of his preferences, but perhaps there is no time or resources available to do that (or even there is no will to do it). Nevertheless, we have to suggest a recommendation and we have to do it here and now. An approach could be to look for a contingent rationality model without searching for it outside the decision process, but within it. Obviously the validity of such a model is strictly local, but its legitimation is clear: the client himself. I will call such an approach prescriptive.

Identifying such a model of rationality has to obey the constraints of the formal language we are using and take in account what the procedures can and cannot do with the available information (see the discussion in [45]). The reader can consult [26], [28], [169], [187], [309], [315], [319], [330] for a discussion of such an approach. The fact that we do not impose a model of rationality, but that we look for it within the problem situation, allows us to be more pragmatic and not to force the client to accept a model of rationality imposed from outside. However, we have to recognise two hypotheses within such an approach: the first is that the client's problem is what it has been presented to us and the second is that the client has a model of rationality (possibly a very personal one). The issue is to identify it.

The reality of decision aiding is that quite often the client does not have a very clear idea of the problem, at least not enough clear to allow the identification of a model of rationality. Are we sure these are all the possible diagnoses? Did we really consider all the possible treatments? Is it certain that the problem is to find a treatment for the client? What if at the end we discover that the best thing to do for the client is to take a long vacation (possibly together with the analyst)? In other terms, finding the solution of a well formulated problem is always possible. The risk is to find a solution to a problem the client does not have. The problem is that nobody really knows what the problem is. In such situations we might adopt an approach which I will call constructive: we have to construct at the same time the problem and its solution.

Within such an approach we do not have to look just for what is the method that better adapts to the client's problem. Together with the client we have to establish a representation of the problem situation, formulate a formal problem with the consensus of the client and then establish an evaluation model which will help to formulate the final recommendation. There is a fundamental learning dimension in such a process. The models we are going to formulate are the result of a mutual 
learning process: the client learns to reason about his problem in an abstract and formal way (the point of view of the analyst) and the analyst learns to reason about the client's problem following the client's point of view. Nothing can be considered as given or fixed and everything has to constructed. The reader can see in [28], [45], [63], [126], [143], [184], [185], [186], [251], [261], [268], [328] more references to such an approach.

In table 1 (borrowed from [83]) I present the principal differences of the different approaches.

\begin{tabular}{|c|c|c|}
\hline Approach & Characteristics & Process to obtain the model \\
\hline Normative & $\begin{array}{l}\text { Exogenous rationality, } \\
\text { ideal economic behaviour }\end{array}$ & To postulate \\
\hline Descriptive & $\begin{array}{l}\text { Exogenous rationality, } \\
\text { empirical behaviour models }\end{array}$ & To observe \\
\hline Prescriptive & $\begin{array}{l}\text { Endogenous rationality, coherence } \\
\text { with the decision situation }\end{array}$ & To unveil \\
\hline Constructive & $\begin{array}{l}\text { Learning process, coherence } \\
\text { with the decision process }\end{array}$ & To reach a consensus \\
\hline
\end{tabular}

Table 1: Differences among approaches

I will add some remarks ending this presentation.

1. It is clear (to me) that the differences among the approaches does not concern the methods used to solve a decision problem. It is possible to use a constructive approach and a combinatorial optimisation procedure if this fits to the situation. On the other hand imposing on the client the use of a method (as flexible as possible) corresponds, to my opinion, in using a normative or a descriptive approach since the legitimation of this choice is external to the client.

2. There is no unique model of rationality and rational behaviour. A client exhibiting "cyclic preferences" is not less rational than another client perfectly consistent with decision theory's axioms. Transitivity of preferences is necessary only if we interpret the sentence " $x$ is preferred to $y$ " as "I am ready to pay more for $x$ than for $y$ ". If we interpret the same sentence as "there are more reasons in favour of $x$ than in favour of $y$ " (see [268], [301]) then it is possible to understand that "cyclic preferences" (in this case) are due to the existence of a cyclic structure of arguments (it is exactly the case with Condorcet's paradox, [72]).

3 . The presence of inconsistency in the client's arguments is not necessary a problem, it can be seen as a source of information for conducting the decision aiding process.

4. Conducting a decision aiding process is a decision aiding itself. Asking the 
question: "where do you want to go this evening?" implies that the set of alternatives is constrained to only external locations, the possibility of remaining at home not being considered. Asking "do you prefer to hear classic music or jazz" implies that the subject wants to hear music, the silence not being considered. This type of implicit hypotheses enters the decision model just by the way in which the decision aiding process is conducted and should be an important source of reflection in our profession.

In the following I will focus on this last concept (the decision aiding process) in order to see how its structuring allows decision theory to operate in practice.

\section{The decision aiding process}

As already noted, Simon has suggested that a "decision" is not an "act", but a process. Following such a suggestion, rationality cannot be conceived with respect to an objective (substantial rationality), but with respect to the process itself (procedural rationality). Rationality becomes a local coherence (with respect to a certain temporal instance of the process) and therefore is bounded (see [282],[285]). In the following I will use a descriptive model of the decision process presented in [231].

In my presentation I will assume that the client is involved within one or more decision processes and that his demand for decision support refers to one of these decision processes. I will group the activities associated to such a support under the name of "decision aiding process" and I will identify the following elements: - at least two participants, the client and the analyst;

- at least two objects of the process: the client's concerns and the analyst's motivations;

- a set of resources including the client's knowledge on his concern's domain, the analyst's methodological knowledge and the time;

- a converging object (a meta-object) consisting in a shared (among the participants) representation of the client's concerns (one or more artifacts, [98],[283]).

I consider the decision aiding process as a distributed cognition process. Nevertheless, my point of view will be operational and not cognitive. I make the hypothesis that the participants actively try to create a shared representation. I will try to analyse the artifacts such a process generates (for an expanded discussion see [235], [291]):

- a representation of the problem situation;

- a problem formulation;

- an evaluation model;

- a final recommendation. 


\subsection{The problem situation}

A representation of the problem situation is the result of an effort aimed at replying to questions of the type:

- who has a problem?

- why this is a problem?

- who decides on this problem?

- what is the commitment of the client on this problem?

- who is going to pay for the consequences of a decision?

The construction of such an artifact allows, on the one hand, the client to better understand his position within the decision process for which he asked the decision support and on the other hand, the analyst to better understand his role within this decision process.

From a formal point of view, a representation of the problem situation is a triplet:

$$
\mathcal{P}=\langle\mathcal{A}, \mathcal{O}, \mathcal{S}\rangle
$$

where:

- $\mathcal{A}$ is the set of participants to the decision process;

- $\mathcal{O}$ is the set of stakes each participant brings within the decision process;

- $\mathcal{S}$ is the set of resources the participants commit on their stakes and the other participants' stakes.

Such a representation is not fixed once and for all within the decision aiding process, but usually will evolve. Actually one reason that such a representation is constructed is to help to understand the misunderstandings during the client analyst interaction.

\subsection{The problem formulation}

For a given representation of the problem situation the analyst might propose to the client one or more "problem formulations". This is a crucial point of the decision aiding process. The representation of the problem situation has a descriptive or explicative scope. The construction of the problem formulation introduces what I have called a model of rationality. A problem formulation reduces the reality of the decision process within which the client is involved to a formal and abstract problem. The result is that one or more of the client's concerns are transformed into formal problems on which we can apply a method (already existing, adapted from an existing one or created ad-hoc) of the type studied in decision theory.

Example 4.1. Consider the case of a client having the problem "to buy new buses in order to improve the service offered to the customers". Different problem for- 
mulation are possible:

- choose one among the potential suppliers;

- choose one among the offers received (a supplier may have done more than one); - choose combinations of offers;

The choice of one among the above formulations is not neutral. The first is focussed on the suppliers rather than the offers and enables us to think about the will to establish a more strategic relation with one of them. The second one is a more contingent formulation and introduces the implicit hypothesis that all buses will be bought from the same supplier. The third is also a contingent problem formulation, but also considers the possibility of buying from different suppliers. Obviously choosing one of the above formulations will strongly influence the outcome of the decision aiding process and the final decision.

From a formal point of view a problem formulation is a triplet:

$$
\Gamma=\langle\mathbb{A}, \mathbb{V}, \Pi\rangle
$$

where:

- $\mathbb{A}$ : is the set of potential actions the client may undertake within the problem situation as represented in $\mathcal{P}$;

$-\mathbb{V}$ : is the set of points of view under which the potential actions are expected to be observed, analysed, evaluated, compared, including different scenarios for the future;

- $\Pi$ : is the problem statement, the type of application to perform on the set $\mathbb{A}$, an anticipation of what the client expects (the reader can see more details on this point in [14], [230], [262]; for a detailed example see, [291]).

Obtaining the client's consensus on a problem formulation can lend insight, since instead of having an "ambiguous" description of the problem we have an abstract and formal problem. Several decision aiding approaches will stop here, considering that formulating (and understanding) a problem is equivalent to solving it, thus limiting decision aiding in helping to formulate problems, the solution being a personal issue of the client. Other approaches instead will consider the problem formulation as given. Within a constructive approach the problem formulation is one among the products of the decision aiding process. It is expected to be used in order to construct the evaluation model.

\subsection{The evaluation model}

By "evaluation model" I indicate what traditionally are the decision aiding models conceived through any operational research, decision theory or artificial intelligence method. Classic decision aiding textbooks focus their attention on the con- 
struction of this model. In a normative approach there is no freedom, the structure of the model being predefined. Within other approaches more degrees of freedom are possible, at least as far as some of the model's parameters are concerned.

An evaluation model is an n-uplet:

$$
\mathcal{M}=\langle A, D, E, H, \mathcal{U}, \mathcal{R}\rangle
$$

where:

- $A$ is a set of alternatives to which the model will apply;

- $D$ is a set of dimensions (attributes) under which the elements of $A$ are observed, measured, described etc. (such a set can be structured, for instance through the definition of an hierarchy);

- $E$ is a set of scales associated to each element of $D$;

- $H$ is a set of criteria (if any) under which each element of $A$ is evaluated in order to take into account the client's preferences (recall that a criterion is a preference model);

$-\mathcal{U}$ is a set of uncertainty measures associated to $D$ and/or $H$;

- $\mathcal{R}$ is a set of operators enabling to obtain synthetic information about the elements of $A$ or of $A \times A$, namely aggregation operators (acting on preferences, measures, uncertainties etc.).

The reader can observe that a large part of the existing decision aiding models and methods can be represented through the above description. Besides, such a description allows to focus our attention on a number of important remarks:

1. It is easy to understand why the differences among the decision aiding approaches do not depend on the adopted decision aiding method. The fact that we work with only one evaluation dimension or a single criterion can be the result of applying a constructive approach. We can conduct a decision aiding process constructively and end by using a combinatorial optimisation algorithm. What is important is to show that such tools are a consequence of the decision aiding process and not to choose them before the problem has been formulated or the evaluation model constructed.

2. The technical choices (typology of the measurement scales, different preference or difference models, different aggregation operators) are not neutral. Even when the client can formulate his problem clearly and is convinced about its formulation (possibly using one of the techniques aiding in formulating problems), the choice of a certain technique, procedure or operator can have important consequences that are not discussed at the moment when the problem has been formulated (for a critical discussion see [45]). Characterising such techniques, procedures and operators is therefore crucial, since it allows a control of their applicability to the problem as has been formulated during the decision aiding process. 
3. The evaluation models are subject to validation processes, namely (see [185]):

- conceptual validation (verify the suitability of the concepts used);

- logical validation (verify the logical consistency of the model);

- experimental validation (verify the results using experimental data);

- operational validation (verify the implementation and use of the model in everyday life).

\subsection{The final recommendation}

The final recommendation represents the return to reality for the decision aiding process. Usually the evaluation model will produce a result, let's call it $\Phi$. The final recommendation should translate such a result from the abstract and formal language in which $\Phi$ is formulated to the current language of the client and the decision process where he is involved. Some elements are very important in constructing this artifact:

- the analyst has to be sure that the model is formally correct;

- the client has to be sure that the model represents him, that he understands it and that he should be able to use its conclusions (the client should feel he is the "owner"'of the results, besides being satisfied by them);

- the recommendation should be "legitimated" with respect to the decision process for which the decision aiding has been asked.

We should pay some attention to this last observation. The decision aiding process is an activity that introduces a certain distance between the participants on the one hand and the reality of the decision process and its organisational dimension on the other hand. Returning back to reality requires a check as to whether the results are legitimated. We should check whether such results are accepted or not by the participants to the decision process and understand the reasons for their position (such reasons can be completely independent from the decision process itself). Being able to put in practice the final recommendation definitely depends on such legitimation. No legitimation, no implementation (see [67]).

Concluding the presentation of the decision aiding process through its artifacts I would like to make two remarks.

- Not all such artifacts are necessarily created in all decision aiding processes. There might be cases where the evaluation model is not constructed, the client being satisfied by being enabled to formulate correctly his problem. A final recommendation might not always be formulated. This presentation tries to give an account of the possible outcomes of a decision aiding process. 
- The identification of artifacts within the decision aiding process under form of "checklists" is of course a simplification of the complexity of real decision aiding situations. The scope of such a presentation is mainly conceived for "training" purposes: what a "novice" analyst should check when involved in a decision aiding process. Experienced analysts may conduct a decision aiding process in a more "holistic" way, but the analysis of such an approach goes beyond the scope of this paper.

\section{Conclusion}

In this paper I have tried to outline a personal perspective on the evolution of decision theory. In such a presentation I mainly focussed on the appearance and growth of several alternative approaches to the so called "classic decision theory" and that in relation both with empirical validation and with the evolution of related scientific domains such as cognitive sciences, organisation theory and artificial intelligence.

A first hypothesis I tried to develop in the paper is that such "alternative approaches" are ultimately related to the "classic decision theory", since they all share the fundamental idea that decision making and decision aiding are human activities that can be scientifically investigated and that it is possible to use an abstract and formal language in aiding decision makers to handle the issues arising within the decision processes they are involved in. I would rather adopt the plural "decision theories" to emphasise the existence of several different theoretical approaches and methods studying and implementing the above idea (see [334]).

A second hypothesis I tried to develop in the paper is that decision aiding is a broader concept than the one of decision theory, since it includes not only the theoretical aspects of this activity, but also the practices and the behaviours that can be observed along what I call the decision aiding process. One of the characteristics of the "decision theories" evolution is the appearance of approaches aiming at including large parts of the decision aiding process in their field of investigation.

I do believe that decision aiding is practiced everyday by individuals and organisations and that, in a proportion of cases that is larger than what the number of relevant scientific publications would suggest, decision theories are correctly used. It should be noted that the level of analysis of such decision aiding practices is far less important if compared to the extremely fine theoretical achievements the "decision theories" can show. Under such a perspective our scientific area, despite its maturity, is still lacking the establishment of "best practices analysis" as it is the case for similar professions including lawyers, physicians and psychotherapists.

A third hypothesis I tried to develop in the paper concerns what decision theory and operational research owns to other scientific fields such as mathematics, cogni- 
tive science, organisation theory, artificial intelligence and more general computer science. Several critical advances in our field have been possible thanks to the integration of findings obtained in such areas. At the same time, the focus of our research on concepts such as decision, preference, optimal and compromise solution etc. provided invaluable contributions to these areas (not only, OR and decision decision theory is applied in fields such as molecular biology, archaeology, engineering, sociology and political science). The ultimate interdisciplinary nature of decision theory and decision aiding can be best observed through its practice.

Last, but not least, I tried to suggest my personal classification of the "decision aiding approaches". In order to do that I tried to establish the differences among such approaches on the basis of the origin of the "model of rationality" used in order to construct the artifacts of the decision aiding process. Under such a perspective I also tried to outline a model of the decision aiding process, sufficiently large to include most of the existing methods and techniques. I thus hope to contribute to the establishment of a "decision aiding methodology" (from the greek $\mu \varepsilon \theta o \delta o \lambda o \gamma i ́ \alpha: \lambda o ́ \gamma o \varsigma \mu \varepsilon \theta o ́ \delta \omega v$, reasoning about methods).

\section{Acknowledgements}

This paper has been initiated while I was visiting DIMACS, Rutgers University, under a NSF CCR 00-87022 grant. It has been finished, while visiting the SMG, Université Libre de Bruxelles under a FNRS grant. Both supports are gratefully acknowledged. In order to compile the historical part of this essay I have extensively used the 50 year history compiled by S. Gass for INFORMS ([125]). Ofer Melnik at DIMACS helped me in writing reasonable English. I am indebted to Ken Bowen, Luis Dias, Marc Pirlot and Bernard Roy for some very interesting discussions on earlier versions of this paper. Three anonymous referees provided helpful comments which definitely improved the text. However, I remain solely responsible for this essay. The fact that in this text decision makers, clients and analysts are all male is not a provocation of political incorrectness, but just a convention.

\section{References}

[1] L. Åqvist. Deontic logic. In D. Gabbay and F. Guenther, editors, Handbook of Philosophical Logic, vol II, pages 605-714. D. Reidel, Dordrecht, 1986.

[2] E. Aarts and J.K. Lenstra. Local search in combinatorial optimization. J. Wiley, New York, 1997. 
[3] R.L. Ackoff. Some unsolved problems in problem solving. Operational Research Quarterly, 13:1-11, 1962.

[4] R.L Ackoff. The future of operational research is past. Journal of Operational Research Society, 30:93-104, 1979.

[5] R.L. Ackoff. Resurrecting the future of operational research. Journal of the Operational Research Society, 30:189-199, 1979.

[6] R.M. Adelson and J.M. Norman. Operational research and decision making. Operational Research Quarterly, 20:399-413, 1969.

[7] C. Alchourron, P. Gärdenfors, and D. Makinson. On the logic of theory change: Partial meet contraction and revision functions. Journal of Symbolic Logic, 50:510-530, 1985.

[8] M. Allais. Le comportement de l'homme rationnel devant le risque : Critique des postulats et axiomes de l'école américaine. Econometrica, 21:50346, 1953.

[9] M. Allais and O. Hagen, editors. Expected utility hypotheses and the Allais paradox. D. Reidel, Dordrecht, 1979.

[10] Kr. Apt. The essence of constraint propagation. Theoretical Computer Science, 221:179-210, 1999.

[11] Aristotle. Ethica Nicomachea. Oxford University Press, Oxford, 1990. Originally published in $350 \mathrm{bc}$, english edition by I. Bywater.

[12] K.J. Arrow. Social choice and individual values. J. Wiley, New York, 1951. 2nd edition, 1963.

[13] W.R. Ashby. An introduction to cybernetics. Chapman \& Hall, London, 1956.

[14] C.A. Bana e Costa. Les problématiques de l'aide à la décision : vers l'enrichissement de la trilogie choix-tri-rangement. RAIRO/ Recherche Opérationnelle, 30(2):191-216, 1996.

[15] C.A. Bana e Costa, F.N. da Silva, and J.-C. Vansnick. Conflict dissolution in the public sector: A case-study. European Journal of Operational Research, 130:388-401, 2001. 
[16] C.A. Bana e Costa, L. Ensslin, E.C. Correa, and J.-C. Vansnick. Decision support systems in action: Integrated application in a multicriteria decision aid process. European Journal of Operational Research, 113:315-335, 1999.

[17] C.A. Bana e Costa and J.C. Vansnick. MACBETH: An interactive path towards the construction of cardinal value functions. International Transactions in Operational Research, 1(4):387-500, 1994.

[18] C. Banville, M. Landry, J.-M. Martel, and C. Boulaire. A stakeholder approach to MCDA. Systems Research and Behavioral Science, 15:15-32, 1998.

[19] P. Barth and A. Bockmayr. Modelling discrete optimisation problems in constraint logic programming. Annals of Operations Research, 81:467-495, 1998.

[20] J.-P. Barthelemy, R. Bisdorff, and G. Coppin. Human centered processes and decision support systems. European Journal of Operational Research, 136:233-252, 2002.

[21] J.-P. Barthélemy and E. Mullet. A model of selection by aspects. Acta Psychologica, 79:1-19, 1992.

[22] G. Bateson. Steps to an Ecology of Mind. Chandler Publ. Group, S. Francisco, 1972.

[23] S. Beer. What has cybernetics to do with operational research? Operational Research Quarterly, 10:1-21, 1959.

[24] S. Beer. Decision and control; the meaning of operational research and management cybernetics. J. Wiley, New York, 1966.

[25] S. Beer. Brain of the firm. Herder and Herder, New York, 1972. 2nd edition in 1981 by J. Wiley, New York.

[26] D. Bell, H. Raiffa, and A. Tversky, editors. Decision making: descriptive, normative, and prescriptive interactions. Cambridge university press, Cambridge, 1988.

[27] V. Belton, F. Ackermann, and I. Shepherd. Integrated support from problem structuring through alternative evaluation using COPE and V-I-S-A. Journal of Multi-Criteria Decision Analysis, 6:115-130, 1997. 
[28] V. Belton and T. Stewart. Muliple Criteria Decision Analysis: An Integrated Approach. Kluwer Academic, Dordrecht, 2002.

[29] R. Benayoun, J. de Montgolfier, J. Tergny, and O.I. Larichev. Linear programming with multiple objective functions: Step method (STEM). Mathematical Programming, 1(3):366-375, 1971.

[30] R. Benayoun, B. Roy, and B. Sussman. ELECTRE: une méthode pour guider le choix en présence des points de vue multiples. Technical report, SEMA-METRA International, Direction Scientifique, 1966. Note de travail 49.

[31] C. Berge. Théorie des graphes et ses applications. Collection Univesitaire des Mathématiques, Dunod, Paris, 1958.

[32] D. Bernoulli. Specimen theoriae novae de mensura sortis, Commentarii Academiae Scientiarum Imperialis Petropolitanae (5, 175-192, 1738). Econometrica, 22:23-36, 1954. Translated by L. Sommer.

[33] R. Bisdorff. Logical foundation of fuzzy preferential systems with application to the ELECTRE decision aid methods. Computers \& Operations Research, 27(7-8):673-687, June 2000.

[34] P.M.S. Blackett. Operational research. Operational Research Quarterly, 1:3-6, 1950. Now Journal of the Operational Research Society.

[35] H. Bleichrodt, J.L. Pinto, and P.P. Wakker. Making descriptive use of prospect theory to improve the prescriptive use of expected utility. Management Science, 47:1498 - 1514, 2001.

[36] A. Bockmayr and T. Kasper. Branch and infer: a unifying framework for integer and finite domain constraint programming. Informs Journal on Computing, 10:287-300, 1998.

[37] B. Bonet and H. Geffner. Arguing for decisions: A qualitative model of decision making. In Uncertainty in Artificial Intelligence: Proceedings of the Twelfeth Conference (UAI-1996), pages 98-105. Morgan Kaufmann, San Francisco, 1996.

[38] J.C. Borda. Mémoire sur les élections au scrutin. Comptes rendus de l'Académie des sciences, traduit par Alfred de Grazia comme Mathematical Derivation of a election system, Isis, vol 44, pp 42-51, 1781. 
[39] C. Boutilier. Toward a logic for qualitative decision theory. In Proceedings of the 4th International Conference on Knowledge Representation and Reasoning, KR'94, pages 75-86. Morgan Kaufmann, San Francisco, 1994.

[40] C. Boutilier. Knowledge representation for stochastic decision processes. In M.J Wooldridge and M. Veloso, editors, Artificial intelligence today. Recent trends and developments, pages 111-152. Springer Verlag, Berlin, 1999.

[41] C. Boutilier. Decision making under uncertainty: operations research meets AI (again). In Proceedings of the 17th National Conference on Artificial Intelligence, AAAI-2000, pages 1145-1150. AAAI Press, Menlo Park, 2000.

[42] C. Boutilier, T. Dean, and S. Hanks. Decision-theoretic planning: Structural assumptions and computational leverage. Journal of Artificial Intelligence Research, 11:1-94, 1999.

[43] D. Bouyssou. Democracy and efficiency - A note on 'Arrow's theorem is not a surprising result'. European Journal of Operational Research, 58:427430, 1992.

[44] D. Bouyssou. La crise de la recherche opérationnelle: 25 ans après. Mathématiques et Sciences Humaines, 161:7-27, 2003.

[45] D. Bouyssou, T. Marchant, M. Pirlot, P. Perny, A. Tsoukiàs, and Ph. Vincke. Evaluation and decision models: a critical perspective. Kluwer Academic, Dordrecht, 2000.

[46] D. Bouyssou, T. Marchant, M. Pirlot, A. Tsoukiàs, and Ph. Vincke. Evaluation and decision models: stepping stones for the analyst. Springer Verlag, Berlin, 2006.

[47] D. Bouyssou, P. Perny, M. Pirlot, A. Tsoukiàs, and Ph. Vincke. A manifesto for the new MCDM era. Journal of Multi-Criteria Decision Analysis, 2:125127, 1993.

[48] D. Bouyssou and M. Pirlot. Non transitive decomposable conjoint measurement. Journal of Mathematical Psychology, 46:677-703, 2002.

[49] D. Bouyssou and M. Pirlot. 'Additive difference' models without additivity and subtractivity. Journal of Mathematical Psychology, 48:263-291, 2004.

[50] D. Bouyssou and M. Pirlot. Preferences for multiattributed alternatives: Traces, dominance, and numerical representations. Journal of Mathematical Psychology, 48:167-185, 2004. 
[51] D. Bouyssou and M. Pirlot. A characterization of concordance relations. European Journal of Operational Research, 167:427-443, 2005.

[52] D. Bouyssou and M. Pirlot. Following the traces: An introduction to conjoint measurement without transitivity and additivity. European Journal of Operational Research, 163:287-337, 2005.

[53] K. Bowen. Sixty years of operational research. European Journal of Operational Research, 153:618-623, 2004.

[54] R.I. Brafman and N. Friedman. On decision-theoretic foundations for defaults. Artificial Intelligence, 133:1-33, 2001.

[55] R.I. Brafman and M. Tennenholtz. On the foundations of qualitative decision theory. In Proceedings of the 13th National Conference on Artificial Intelligence, AAAI96, pages 1291-1296. MIT Press, Cambridge, 1996.

[56] R.I. Brafman and M. Tennenholtz. Modeling agents as qualitative decision makers. Artificial Intelligence, 94:217-268, 1997.

[57] R.I. Brafman and M. Tennenholtz. An axiomatic treatment of three qualitative decision criteria. Journal of the ACM, 47:452-482, 2000.

[58] S.C. Brailsford, C.N. Potts, and B.M. Smith. Constraint satisfaction problems: algorithms and applications. European Journal of Operational Research, 119:557-581, 1999.

[59] A. Caprara, P. Toth, D. Vigo, and M. Fischetti. Modeling and solving the crew rostering problem. Operations Research, 46:820-830, 1998.

[60] A. Charnes and W.W. Cooper. Management models and industrial applications of linear programming. J. Wiley, New York, 1961.

[61] A. Charnes, W.W. Cooper, and R. Ferguson. Optimal estimation of executive compensation by linear programming. Management Science, 1:138$151,1955$.

[62] A. Chateauneuf and P.P. Wakker. An axiomatization of cumulative prospect theory for decision under risk. Journal of Risk and Uncertainty, 18:137145, 1999.

[63] P. Checkland. Systems thinking, systems practice. J. Wiley, New York, 1981.

[64] P. Checkland and J. Scholes. Soft Systems Methodology in Action. J. Wiley, New York, 1990. 
[65] R.M. Chisholm and E. Sosa. Intrinsic preferability and the problem of supererogation. Synthese, 16:321-331, 1966.

[66] R.M. Chisholm and E. Sosa. On the logic of intrinsically better. American Philosophical Quarterly, 3:244-249, 1966.

[67] C.W. Churchman. Wicked problems. Management Science, 14:B141-B142, 1967.

[68] C.W. Churchman, R.L. Ackoff, and E.L. Arnoff. Introduction to Operations Research. J. Wiley, New-York, 1957.

[69] J.L. Cochrane and M. Zeleny. Multiple Criteria Decision Making. University of South Carolina Press, Columbia, 1973.

[70] M. Cohen and J.-Y Jaffray. Rational behavior under complete ignorance. Econometrica, 48:1281-1299, 1980.

[71] M.D. Cohen, J.G. March, and J.P. Olson. A garbage can model of organizational choice. Administrative Science Quarterly, 17:1-25, 1972.

[72] Marquis de Condorcet. Essai sur l'application de l'analyse à la probabilité des décisions rendues à la pluralité des voix. Imprimerie Royale, Paris, 1785 .

[73] R.W. Conway, W.L. Maxwell, and L.W. Miller. Production scheduling. Addison Wesley, Reading, 1967.

[74] C.H. Coombs. On the use of inconstistency in preferences in psychological measurement. Journal of Experimental Psychology, 55:1-7, 1958.

[75] J.D. Croston and G. Gregory. A critique of "Operational Research and Decision Making" by Adelson and Norman. Operational Research Quarterly, 20:215-220, 1969.

[76] R.M. Cyert and J.G. March. A Behavioral Theory of the Firm. Prentice Hall, Englewood Cliffs, 1963.

[77] H.G. Daellenbach. Systems and decision making. A management science approach. J. Wiley, New York, 1994.

[78] G.B. Dantzig. Programming in a linear structure. USAF, Washington D.C., 1948. 
[79] G.B. Dantzig. Application of the simplex method to a transportation problem. In T.C. Koopmans, editor, Activity analysis of production and allocation, pages 359-373. J. Wiley, New York, 1951.

[80] G.B. Dantzig. Linear Programming and Extensions. Princeton University Press, Princeton, 1963.

[81] B. de Finetti. La logique de la probabilité. In Actes du Congres International de Philosophie Scientifique a Paris 1935, Tome IV, pages 1-9. Hermann et Cie, Paris, 1936.

[82] B. de Finetti. La prévision: Ses lois logiques, ses sources subjectives. In Annales de l'Institut Henri Poincaré 7, pages 1-68. Paris, 1937. Translated into English by Henry E. Kyburg Jr., Foresight: Its Logical Laws, its Subjective Sources. In Henry E. Kyburg Jr. and Howard E. Smokler (1964, Eds.), Studies in Subjective Probability, 53-118, Wiley, New York.

[83] L.C. Dias and A. Tsoukiàs. On the constructive and other approaches in decision aiding. In C.A Hengeller Antunes, J. Figueira, and J. Clímaco, editors, Proceedings of the 56th meeting of the EURO MCDA working group, pages 13-28. CCDRC, Coimbra, 2004.

[84] J.P Doignon, B. Monjardet, M. Roubens, and Ph. Vincke. Biorder families, valued relations and preference modelling. Journal of Mathematical Psychology, 30:435-480, 1986.

[85] J. Doyle. Reasoned assumptions and Pareto optimality. In Proceedings of the 9th International Joint Conference on Artificial Intellignce, IJCAI85, pages 87-90. Morgan Kaufmann, San Francisco, 1985.

[86] J. Doyle. Constructive belief and rational representation. Computational Intelligence, 5:1-11, 1989.

[87] J. Doyle. Rationality and its roles in reasoning. In Proceedings of the 8th National Conference on Artificial Intelligence (AAAI'90), pages 1093-1100. MIT Press, Cambridge, 1990.

[88] J. Doyle. Reasoned assumptions and rational psychology. Fundamenta Informaticae, 20:35-73, 1994.

[89] J. Doyle, Y. Shoham, and M.P. Wellman. A logic of relative desire. In Methodologies for Intelligent Systems, 6th International Symposium, ISMIS 91, pages 16-31. Springer-Verlag, Berlin, 1991. 
[90] J. Doyle and R.H Thomason. Background to qualitative decision theory. AI Magazine, 20:55-68, 1999.

[91] J. Doyle and M.P. Wellman. Impediments to universal preference-based default theories. Artificial Intelligence, 49:97-128, 1991.

[92] J. Doyle and M.P. Wellman. Representing preferences as ceteris paribus comparatives. In Decision-Theoretic Planning: Papers from the 1994 Spring AAAI Symposium, pages 69-75. AAAI Press, Menlo Park, California, 1994.

[93] D. Dubois, H. Fargier, P. Perny, and H. Prade. Qualitative decision theory: from Savage's axioms to non-monotonic reasoning. Journal of the ACM, 49:455-495, 2002.

[94] D. Dubois, H. Fargier, and H. Prade. Possibility theory in constraint satisfaction problems: handling priority, preference and uncertainty. Applied Intelligence, 6:287-309, 1996.

[95] D. Dubois and H. Prade. Possibility theory. Plenum Press, New-York, 1988.

[96] D. Dubois and H. Prade. Possibility theory as a basis for qualitative decision theory. In Proceedings of the 14th International Joint Conference on Artificial Intelligence, IJCAI95, pages 1924-1930. Morgan Kaufmann, San Francisco, 1995.

[97] B. Dushnik and E.W. Miller. Partially ordered sets. American Journal of Mathematics, 63:600-610, 1941.

[98] S. Easterbrook. Handling conflict between domain descriptions with computer-supported negotiation. Knowledge Acquisition, 3:255-289, 1991.

[99] C. Eden. Cognitive mapping. European Journal of Operational Research, 36:1-13, 1988.

[100] C. Eden, S. Jones, and D. Sims. Messing About in Problems. Pergamon Press, Oxford, 1983.

[101] W. Edwards. The theory of decision making. Psychological Bulletin, 41:380-417, 1954.

[102] M. Ehrgott and X. Gandibleux. Multiple Criteria Optimization. State of the art annotated bibliographic surveys. Kluwer Academic, Dordrecht, 2002.

[103] R. Emerson. Power dependence relations. American Sociological Review, 27:31-41, 1962. 
[104] F. Emery. Characteristics of socio-technical systems. Technical report, Tavistock Institute, Document 527, London, 1959.

[105] L. Euler. Solutio problematis ad geometriam situs pertinentis. Opera Omnia, 7:128-140, 1736.

[106] R. Faure. Éléments de la recherche opérationnelle. Gauthier-Villars, Paris, 1968.

[107] H. Fayol. General and Industrial Management. Pitman and Sons, New York, 1949. First edition in 1916.

[108] L. Festinger. Conflict, decision and dissonance. Stanford University Press, Stanford, 1964.

[109] R. Fikes and N. Nilsson. Strips: A new approach to the application of theorem proving to problem solving. Artificial Intelligence, 2:189-208, 1971.

[110] P.C. Fishburn. Utility Theory for Decision Making. Wiley, New York, 1970.

[111] P.C. Fishburn. Nontransitive measurable utility. Journal of Mathematical Psychology, 26:31-67, 1982.

[112] P.C. Fishburn. Interval Orders and Interval Graphs. J. Wiley, New York, 1985.

[113] M.M. Flood. The travelling-salesman problem. Operations Research, 6:61$75,1956$.

[114] J. Fodor and M. Roubens. Fuzzy preference modelling and multicriteria decision support. Kluwer Academic Publishers, 1994.

[115] L.R. Ford and D.R. Fulkerson. Flows in Networks. Princeton University Press, Princeton, 1962.

[116] Ph.. Fortemps and R. Slowinski. A graded quadrivalent logic for ordinal preference modelling: Loyola-like approach. Fuzzy Optimization and Decision Making, 1:93-111, 2002.

[117] S. French. Decision theory - An introduction to the mathematics of rationality. Ellis Horwood, Chichester, 1988.

[118] J.K. Friend and A. Hickling. Planning under pressure: the strategic choice approach. Pergamon Press, New York, 1987. 
[119] J.K. Friend and W.N. Jessop. Local Government and Strategic Choice. Tavistock Publications, London, 1969.

[120] P. Gärdenfors. Knowledge in flux. MIT Press, Cambridge, 1988.

[121] P. Gärdenfors and D. Makinson. Nonmonotonic inference based on expectations. Artificial Intelligence, 65:197-245, 1994.

[122] L.R. Gardiner and D. Vanderpooten. Interactive multiple criteria procedures: Some reflections. In J.N. Clíimaco, editor, Multicriteria Analysis, pages 290-301. Springer Verlag, Berlin, 1997.

[123] M. Garey and D. Johnson. Computers and Intractability. Freeman and Co., New York, 1979.

[124] S.I Gass. Linear Programming: Methods and Applications. Mc Graw Hill, New York, 1958.

[125] S.I. Gass and A.A. Assad. An Annotated Timeline of Operations Research: An Informal History. Springer Verlag, Berlin, 2005.

[126] J.-L. Genard and M. Pirlot. Multiple criteria decision aid in a philosophical perspective. In D. Boyssou, E. Jacquet-Lagrèze, P. Perny, R. Slowinski, D. Vanderpooten, and $\mathrm{Ph}$. Vincke, editors, Aiding decisions with multiple criteria: essays in honour of Bernard Roy, pages 89-117. Kluwer Academic, Dordrecht, 2002.

[127] A.M. Geoffrion. Proper efficiency and the theory of vector optimisation. Journal of Mathematical Analysis and Application, 22:618-630, 1968.

[128] A.M. Geoffrion, J.S. Dyer, and A. Feinberg. An interactive approach for multicriteria optimization with an application to the operation of an accademic department. Management Science, 19:357-369, 1973.

[129] G. Gigerenzer and P.M. Todd. Simple heuristics that make us smart. Oxford University Press, New York, 1999.

[130] I. Gilboa and D. Schmeidler. Maxmin expected utility with a non-unique prior. Journal of Mathematical Economics, 18:141-153, 1989.

[131] I. Gilboa and D. Schmeidler. Updating ambigous beliefs. Journal of Economic Theory, 59:33-49, 1993.

[132] I. Gilboa and D. Schmeidler. A cognitive model of individual well-being. Social Choice and Welfare, 12:269-288, 2001. 
[133] I. Gilboa and D. Schmeidler. A cognitive foundation of probability. Mathematics of Operations Research, 27:68-81, 2002.

[134] I. Gilboa, D. Schmeidler, and P.P. Wakker. Utility in case-based decision theory. Journal of Economic Theory, 105:483-502, 2002.

[135] F. Glover. Future paths for integer programming and links to artificial intelligence. Computers and Operations Research, 13:533-549, 1986.

[136] F. Glover and M. Laguna. Tabu Search. Kluwer Academic, Dordrecht, 1997.

[137] E. Goffman. Asylums; essays on the social situation of mental patients and other inmat. Alding Publishing Co., Chicago, 1968.

[138] D.E. Goldberg. Genetic algorithms in search, optimisation and machine learning. Addison Wesley, Reading, 1989.

[139] P. Goodwin and G. Wright. Decision Analysis for Management Judgment. J. Wiley, New York, 1998. Second Edition.

[140] M. Grabisch, T. Murofushi, M. Sugeno, and J. Kacprzyk. Fuzzy Measures and Integrals. Theory and Applications. Physica Verlag, Berlin, 2000.

[141] M. Grabisch, H.T Nguyen, and E.A Walker. Fundamentals of uncertainty calculi, with applications to fuzzy inference. Kluwer Academic, Dordrecht, 1995.

[142] S. Greco, B. Matarazzo, and R. Slowinski. The use of rough sets and fuzzy sets in MCDM. In T. Gal, T. Stewart, and T. Hanne, editors, Advances in MCDM models, Algorithms, Theory, and Applications, pages 14.1-14.59. Kluwer Academic, Dordrecht, 1999.

[143] J. Habermas. Logic of the social sciences. MIT Press, Boston, 1990.

[144] S. Halldén. On the Logic of Better. Library of Theoria, Lund, 1957.

[145] B. Hansson. Choice structures and preference relations. Synthese, 18:443458, 1966.

[146] B. Hansson. Fundamental axioms for preference relations. Synthese, 18:423-442, 1966.

[147] P.E. Hart, N.J. Nilsson, and B. Raphael. A formal basis for the heuristic determination of minimum cost paths. IEEE Transactions on Systems Science and Cybernetics, 4:100-107, 1968. 
[148] J. Hartmanis and R.E Stearns. On the computational complexity of algorithms. Transactions of the American Mathematical Society, 117:285-305, 1965 .

[149] A. Hatchuel and B. Weil. L'expert et le système. Economica, Paris, 1992.

[150] F.S. Hillier and G.J. Lieberman. Introduction to Operations Research. Holden Day, Oakland, 1967.

[151] R. Hilpinen. Deontic logic: introductory and systematic readings. Reidel, Dordrecht, 1971.

[152] O. Huber. An axiomatic system for multidimensional preferences. Theory and Decision, 5:161-184, 1974.

[153] P.C. Humphreys, O. Svenson, and A. Vári. Analysis and aiding decision processes. North-Holland, Amsterdam, 1983.

[154] E. Jacquet-Lagrèze and Y. Siskos. Assessing a set of additive utility functions for multicriteria decision making: the UTA method. European Journal of Operational Research, 10:151-164, 1982.

[155] J.-Y. Jaffray and P.P. Wakker. Decision making with belief functions: Compatibility and incompatibility with the sure-thing principle. Journal of Risk and Uncertainty, 7:255-271, 1993.

[156] J.Y. Jaffray. Choice under risk and the security factor: An axiomatic model. Theory and Decision, 24:169-200, 1988.

[157] J.Y. Jaffray. Utility theory for belief functions. Operations Research Letters, $8: 107-112,1989$.

[158] B. Jaumard, S.O. Peng, and B. Simeone. A selected artificial intelligence bibliography for operations researchers. Annals of Operations Research, 12:1-50, 1988.

[159] R.C. Jeffrey. The logic of decision. Mc. Graw Hill, New York, 1965.

[160] P. Journée, P. Perny, and D. Vanderpooten. A multicriteria methodology for the verification of arms control agreements in Europe. Foundations of Computing and Decision Sciences, 23(2):64-85, 1998.

[161] J. Kacprzyk and M. Roubens. Non Conventional Preference Relations in Decision Making. Springer Verlag, LNMES n. 301, Berlin, 1988. 
[162] D. Kahneman. A perspective on judgment and choice: Mapping bounded rationality. American Psychologist, 58:697-720, 2003.

[163] D. Kahneman and S. Frederick. Representativeness revisited: Attribute substitution in intuitive judgment. In T. Gilovich, D. Griffin, and D. Kahneman, editors, Heuristics and Biases: The Psychology of Intuitive Judgment, pages 49-81. Cambridge University Press, Cambridge, 2002.

[164] D. Kahneman, P. Slovic, and A. Tversky. Judgement under uncertainty Heuristics and biases. Cambridge University Press, Cambridge, 1981.

[165] D. Kahneman and A. Tversky. Prospect theory: An analysis of decision under risk. Econometrica, 47:263-291, 1979.

[166] L.V. Kantorovich. Mathematical methods in the organisation and planning of production. Publication House of the Leningrad State University, Leningrad, 1939. Translated into english in: Management Science, vol. 6, 1960, 366-422.

[167] R.H. Karp. On the complexity of combinatorial problems. Networks, 5:4468, 1975.

[168] J.X. Kasperson, R.E. Kasperson, N. Pidgeon, and P. Slovic. The social amplification of risk: Assessing fifteen years of research and theory. In N. Pidgeon, R.E. Kasperson, and P. Slovic, editors, The social amplification of risk, pages 13-46. Cambridge University Press, Cambridge, 2003.

[169] R.L. Keeney. Value-Focused Thinking. A Path to Creative Decision Making. Harvard University Press, Cambridge, 1992.

[170] R.L. Keeney, J.S. Hammond, and H. Raiffa. Smart Choices: A Guide to Making Better Decisions. Harvard University Press, Boston, 1999.

[171] R.L. Keeney and H. Raiffa. Decisions with multiple objectives: Preferences and value tradeoffs. J. Wiley, New York, 1976.

[172] J.S. Kelly. Arrow Impossibility Theorems. Academic Press, New York, 1978.

[173] J.S. Kelly. Social choice bibliography. Social Choice and Welfare, 8:97169, 1991.

[174] Hua-Lo Keng. Selected Papers. Springer Verlag, Berlin, 1983. edited by H. Halberstam. 
[175] M.W. Kirby. A history of Operational Research in Britain. World Scientific, London, 2002.

[176] J. Kitainik. Fuzzy decision procedures with binary relations. Kluwer Academic, Dordrecht, 1993.

[177] A.N. Kolmogorov. Grundbegriffe der Warscheinlichkeitsrechnung. Springer, Berlin, 1933. Translated into English by Nathan Morrison (1950), Foundations of the Theory of Probability, Chelsea, New York. Second English edition 1956.

[178] B.O. Koopman. Fallacies in operations research. Operations Research, 3:422-426, 1956.

[179] D.H. Krantz, R.D. Luce, P. Suppes, and A. Tversky. Foundations of measurement, volume 1: Additive and polynomial representations. Academic Press, New York, 1971.

[180] S. Kraus, D. Lehmann, and M. Magidor. Nonmonotonic reasoning, preferential models and cumulative logics. Artificial Intelligence, 44:167-207, 1990.

[181] Mei-Ko Kwan. Graphic programming using odd or even points. Chinese Mathematics, 1:273-277, 1962.

[182] M. Landry. Les rapports entre la complexité et la dimension cognitive de la formulation des problèmes. In L'aide à la décision dans l'organization, AFCET, Paris, pages 3-31, 1987.

[183] M. Landry. A note on the concept of problem. Organization Studies, 16:315-343, 1995.

[184] M. Landry, C. Banville, and M. Oral. Model legitimisation in operational research. European Journal of Operational Research, 92:443-457, 1996.

[185] M. Landry, J.L. Malouin, and M. Oral. Model validation in operations research. European Journal of Operational Research, 14:207-220, 1983.

[186] M. Landry, D. Pascot, and D. Briolat. Can DSS evolve without changing our view of the concept of problem? Decision Support Systems, 1:25-36, 1983.

[187] O.I. Larichev and H.M. Moskovich. Unstructured problems and developmennt of prescriptive decision making methods. In P. Pardalos, Y. Siskos, 
and C. Zopounidis, editors, Advances in Multicriteria Analysis, pages 4780. Kluwer Academic, Dordrecht, 1995.

[188] E. Lawler and A. Rinnooy Kan. The Traveling Salesman Problem: A Guided Tour of Combinatorial Optimization. J. Wiley, New York, 1985.

[189] J.-L. Le Moigne. La Théorie du système général: Théorie de la modélisation. Presses Universitaires de France, Paris, 1977.

[190] D. Lehmann. Generalized qualitative probability: Savage revisited. In Proceedings of the 12th Conference on Uncertainty in Artificial Intelligence, UAI96, pages 381-388. Morgan Kaufmann, San Francisco, 1996.

[191] D. Lehmann. Expected qualitative utility maximization. Games and Economic Behavior, 35:54-79, 2001.

[192] D. Lehmann. Nonmonotonic logics and semantics. Journal of Logic and Computation, 11:229-256, 2001.

[193] J.K Lenstra, A.H.G Rinnooy Kan, and A. Schrijver, editors. History of mathematical programming: a collection of personal reminiscences. North Holland, Amsterdam, 1991.

[194] W. Lichtenstein and P. Slovic. Reversals of preferences between bids and choices gambling decisions. Journal of Experimental Psychology, 89:4655,1971 .

[195] W. Lichtenstein, P. Slovic, and D. Zink. Effect of instruction in expected value on optimality of gambling decisions. Journal of Experimental Psychology, 79:236-240, 1969.

[196] J.D.C. Little, K.G. Murty, D.W. Sweeney, and C. Karel. An algorithm for the travelling salesman problem. Operations Research, 11:972-989, 1963.

[197] R.D. Luce. Semiorders and a theory of utility discrimination. Econometrica, 24:178-191, 1956.

[198] R.D. Luce. The ongiong dialog between empirical science and measurement theory. Journal of Mathematical Psychology, 40:78-98, 1996.

[199] R.D. Luce and H. Raiffa. Games and Decisions. J. Wiley, New York, 1957.

[200] R.D. Luce and D. von Winterfeldt. What common ground exists for descriptive, prescriptive, and normative utility theories? Management Science, 40:263-279, 1994. 
[201] M.J Machina. Expected utility without the independence axiom. Econometrica, 50:277-323, 1982.

[202] M.J Machina and D. Schmeidler. A more robust definition of subjective probability. Econometrica, 60:745-780, 1992.

[203] M.J Machina and D. Schmeidler. Bayes without Bernoulli: Simple conditions for probabilistically sophisticated choice. Journal of Economic Theory, 67:106-128, 1995.

[204] J.G. March and H.A. Simon. Organizations. J.Wiley, New York, 1958.

[205] K. O. May. Intransitivity, utility and the aggregation of preference patterns. Econometrica, 22:1-13, 1954.

[206] J. McCarthy and P.J. Hayes. Some philosophical problems from the standpoint of artificial intelligence. In D. Michie, editor, Machine Intelligence, vol. 4, pages 463-502. Edinburgh University Press, Edinburgh, 1969.

[207] J. Mélèse. Approche systèmique des organisations. Ed. Hommes et Techniques, Paris, 1978.

[208] M. Minsky. A framework for representing knowledge. In P.M Winston, editor, The Psychology of Computer Vision, pages 211-277. McGraw Hill, New York, 1975.

[209] H. Mintzberg. The Structuring of Organizations. Prentice Hall, Englewood Cliffs, 1979.

[210] H. Mintzberg. Power in and around organizations. Prentice Hall, Englewood Cliffs, 1983.

[211] H. Mintzberg, D. Raisinghani, and A. Théoret. The structure of unstructured decision processes. Administrative Science Quarterly, 21:246-272, 1976.

[212] Ph. Mongin. Does optimisation implies rationality? Synthese, 124:73-111, 2000.

[213] H. Montgomery. Decision rules and the search for a dominance structure: towards a process models of decision making. In P.C. Humphreys, O. Svenson, and A. Vári, editors, Analysing and aiding decision processes, pages 343-369. North Holland, Amsterdam, 1983. 
[214] H. Montgomery and O. Svenson. On decision rules and information processing strategies for choices among multiattribute alternatives. Skandinavian Journal of Psychology, 17:283-291, 1976.

[215] G. Morton and A.H. Land. A contribution to the travelling-salesman problem. Journal of the Royal Statistical Society, Series B, 17:185-194, 1942.

[216] J. Moscarola. Organizational decision processes and ORASA intervention. In R. Tomlinson and I. Kiss, editors, Rethinking the process of operational research and systems analysis, pages 169-186. Pergamon Press, Oxford, 1984.

[217] J.D. Mullen. Does the logic of preference rest on a mistake? Metaphilosophy, 10:247-255, 1979.

[218] J.F. Nash. The bargaining problem. Econometrica, 18:155-162, 1950.

[219] J.F. Nash. Non cooperative games. Annals of Mathematics, 54:286-295, 1951.

[220] R.F Nau. Coherent decision analysis with inseparable probabilities and utilities. Journal of Risk and Uncertainty, 10:71-91, 1995.

[221] R.F. Nau. De Finetti was right: Probability does not exist.. Theory and Decision, 51:89-124, 2001.

[222] A. Newell and H.A. Simon. GPS, a program that simulates human thought. In E.A Feigenbaum and J. Feldman, editors, Computers and Thought, pages 279-293. McGraw-Hill, New York, 1963.

[223] A. Newell and H.A. Simon. Human Problem Solving. Prentice Hall, Englewood Cliffs, 1972.

[224] N.J. Nillson. Problem Solving Methods in Artificial Intelligence. McGraw Hill, New York, 1971.

[225] N. Nilsson. Principles of Artificial Intelligence. Tioga, Palo Alto, 1980.

[226] H. Nurmi. Comparing voting systems. D. Reidel, Dordrecht, 1987.

[227] H. Nurmi. Voting paradoxes and how to deal with them? Springer Verlag, Berlin, 1999.

[228] D. Nute. Defeasible deontic logic. Kluwer Academic, Dordrecht, 1997. 
[229] ORSA. Guidelines for the practice of operations research. Operations Research, 19:1123-1148, 1971.

[230] A. Ostanello. Action evaluation and action structuring - Different decision aid situations reviewed through two actual cases. In C.A. Bana e Costa, editor, Readings in multiple criteria decision aid, pages 36-57. Springer Verlag, Berlin, 1990.

[231] A. Ostanello and A. Tsoukiàs. An explicative model of 'public' interorganizational interactions. European Journal of Operational Research, 70:67-82, 1993.

[232] M. Öztürk, A. Tsoukiàs, and Ph Vincke. Preference modelling. In M. Ehrgott, S. Greco, and J. Figueira, editors, State of the Art in Multiple Criteria Decision Analysis, pages 27 - 72. Springer Verlag, Berlin, 2005.

[233] C.H. Papadimitriou and K. Steiglitz. Combinatorial Optimisation, Algorithms and Complexity. Prentice Hall, Englewood Cliffs, 1982.

[234] V. Pareto. Manuale di Economia Politica. Piccola Biblioteca Scientifica, Milan, 1906. Translated into English by Ann S. Schwier (1971), Manual of Political Economy, MacMillan, London.

[235] E. Paschetta and A. Tsoukiàs. A real world MCDA application: evaluating software. Journal of Multi-Criteria Decision Analysis, 9:205-226, 2000.

[236] Z. Pawlak and R. Slowinski. Decision analysis using rough sets. International Transactions on Operational Research, 1:107-114, 1994.

[237] P. Perny and B. Roy. The use of fuzzy outranking relations in preference modelling. Fuzzy Sets and Systems, 49:33-53, 1992.

[238] P. Perny and A. Tsoukiàs. On the continuous extension of a four valued logic for preference modelling. In Proceedings of the IPMU 1998 conference, Paris, pages 302-309, 1998.

[239] M. Pirlot. General local search methods. European Journal of Operational Research, 92:493-511, 1996.

[240] M. Pirlot and Ph. Vincke. Semi Orders. Kluwer Academic, Dordrecht, 1997.

[241] D. Poole. Decision-theoretic defaults. In Proceedings of the Ninth Biennial Conference of the Canadian Society for Computational Studies of Intelligence, pages 190-197. Morgan Kaufmann, San Francisco, 1992. 
[242] E.C. Poulton. Behavioral decision theory: A new approach. Cambridge University Press, Cambridge, 1994.

[243] J. Quiggin. Generalized expected utility theory - The rank-dependent model. Kluwer Academic, Dordrecht, 1993.

[244] H. Raiffa. Preferences for multi-attributed consequences. Technical report, RM-5868-DOT, The RAND Corporation, Santa Monica, California, 1969.

[245] F.P. Ramsey. Foundations of Mathematics and other Logical Essays. Routledge \& P. Kegan, London, 1931. Collection of papers publishded posthumously, edited by R.B Braithwaite.

[246] N. Rescher. Semantic foundations for the logic of preference. In N. Rescher, editor, The logic of decision and action, pages 37-62. University of Pittsburgh, Pittsburgh, 1967.

[247] N. Rescher. Introduction to Value Theory. Prentice Hall, Englewood Cliffs, 1969.

[248] P. Rivett. The craft of decision modelling. J. Wiley, New York, 1994.

[249] F.S. Roberts. Measurement theory, with applications to Decision Making, Utility and the Social Sciences. Addison-Wesley, Boston, 1979.

[250] J. Rosenhead. An education in robustness. Journal of the Operational Research Society, 29:105-111, 1978.

[251] J. Rosenhead. Rational analysis of a problematic world. J. Wiley, New York, 1989. 2nd revised edition in 2001.

[252] J. Rosenhead. What's the problem? an introduction to problem structuring methods. Interfaces, 26:117-131, 1996.

[253] M. Roubens and Ph. Vincke. Preference Modeling. LNEMS 250, Springer Verlag, Berlin, 1985.

[254] B. Roy. Classement et choix en présence de points de vue multiples: La méthode ELECTRE. Revue Francaise d'Informatique et de Recherche Opérationnelle, 8:57-75, 1968.

[255] B. Roy. Méthodologie multicritère d'aide à la décision. Economica, Paris, 1985. 
[256] B. Roy. Decision-aid and decision-making. European Journal of Operational Research, 45:324-331, 1990.

[257] B. Roy. The outranking approach and the foundations of ELECTRE methods. Theory and Decision, 31:49-73, 1991.

[258] B. Roy. Science de la décision ou science de l'aide à la décision ? Revue Internationale de Systémique, 6:497-529, 1992.

[259] B. Roy. Decision science or decision-aid science? European Journal of Operational Research, 66:184-203, 1993.

[260] B. Roy. On operational research and decision aid. European Journal of Operational Research, 73:23-26, 1994.

[261] B. Roy. Multicriteria Methodology for Decision Aiding. Kluwer Academic, Dordrecht, 1996.

[262] B. Roy and D. Bouyssou. Aide Multicritère à la Décision : Méthodes et Cas. Economica, Paris, 1993.

[263] S. Russel and P. Norvig. Artificial Intelligence: a modern approach. Prentice Hall, New York, 1995.

[264] T.L. Saaty. The Analytic Hierarchy Process, Planning, Piority Setting, Resource Allocation. McGraw-Hill, New york, 1980.

[265] R. Sabbadin. Possibilistic Markov decision processes. Engineering Applications of Artificial Intelligence, 14:287-300, 2001.

[266] R. Sabbadin, H. Fargier, and J. Lang. Towards qualitative approaches to multi-stage decision making. International Journal of Approximate Reasoning, 19:441-471, 1998.

[267] L.J. Savage. The Foundations of Statistics. J. Wiley, New York, 1954. second revised edition, 1972.

[268] G. Schaffer. Savage revisited. In D. Bell, H. Raiffa, and A. Tversky, editors, Decision Making: descriptive, normative and prescriptive interactions, pages 193-235. Cambridge University Press, Cambridge, 1988.

[269] A. Schärlig. Décider sur plusieurs critères, panorama de l'aide à la décision multicritère. Presses Polytechniques Romandes, Lausanne, 1985. 
[270] A. Schärlig. Pratiquer Electre et Prométhée. Presses Polytechniques et Universitaires Romandes, Lausanne, 1996.

[271] D. Schmeidler. Subjective probability and expected utility without additivity. Econometrica, 57:571-587, 1989.

[272] D. Scott and P. Suppes. Foundational aspects of theories of measurement. Journal of Symbolic Logic, 23:113-128, 1958.

[273] A.K. Sen. Collective Choice and Social Welfare. North Holland, Amsterdam, 1970.

[274] A.K. Sen. Choice functions and revealed preferences. Review of Economic Studies, 38:307-317, 1971.

[275] A.K. Sen. Social choice theory. In K.J. Arrow and M.D. Intriligator, editors, Handbook of mathematical economics, volume 3, pages 1073-1181. NorthHolland, Amsterdam, 1986.

[276] A.K. Sen. Internal consistency of choice. Econometrica, 61:495-521, 1993.

[277] R.N. Shepard. On subjectively optimum selection among multiattribute alternatives. In M.W Shelly and G.L Bryan, editors, Human judgement and optimality, pages 257-281. J. Wiley, New York, 1964.

[278] Y. Shoham. Nonmonotonic logic: Meaning and utility. In Proceedings of the 10th International Joint Conference in Artificial Intelligence, IJCAI87, pages 388-393. Morgan Kaufmann, San Francisco, 1987.

[279] H.A. Simon. Administrative behaviour: a study of Decision Making Processes in Administrative Organizations. Mac Millan, New York, 1947.

[280] H.A. Simon. A behavioral model of rational choice. Quarterly Journal of economics, 69:99-118, 1954.

[281] H.A. Simon. Rational choice and the structure of the environment. Psychological Review, 63:129-138, 1956.

[282] H.A. Simon. A behavioural model of rational choice. In H.A. Simon, editor, Models of man: social and rational; mathematical essays on rational human behavior in a social setting, pages 241-260. J. Wiley, New York, 1957.

[283] H.A. Simon. The science of the artificial. MIT Press, Camridge, 1969. 
[284] H.A. Simon. From substantial to procedural rationality. In S.J Latsis, editor, Method and Appraisal in Economics, pages 129-148. Cambridge University Press, Cambridge, 1976.

[285] H.A. Simon. Rational decision making in business organisations. American Economic Review, 69:493-513, 1979.

[286] H.A. Simon. Search and reasoning in problem solving. Artificial Intelligence, 21:7-29, 1983.

[287] P. Slovic, M. Finucane, E. Peters, and D.G. MacGregor. Rational actors or rational fools? implications of the affect heuristic for behavioral economics. The Journal of Socio-Economics, 31:329-342, 2002.

[288] P. Slovic and S. Lichtentstein. The relative importance of probabilities and payoffs in risk taking. Journal of Experimental Psychology Monographs, 78:1-18, 1968.

[289] R. Slowinski, editor. Fuzzy sets in decision analysis, operations research and statistics. Kluwer Academic, Dordrecht, 1998.

[290] R. Slowinski and J. Teghem, editors. Stochastic versus Fuzzy approaches to Multiobjective Mathematical Programming under uncertainty. Kluwer Academic, Dordrecht, 1990.

[291] I. Stamelos and A. Tsoukiàs. Software evaluation problem situations. European Journal of Operational Research, 145:273-286, 2003.

[292] Th.J. Stewart and F.B. Losa. Towards reconciling outranking and value measurement practice. European Journal of Operational Research, 145:645659, 2003.

[293] J. Stringer. Operational research for multi-organizations. Operational Research Quarterly, 8:5-20, 1967.

[294] O. Svenson. Decision making and the search for fundamental psychological regularities: what can we learn from a process perspective? Organisational Behaviour and Human Decision Processes, 65:252-267, 1996.

[295] S.W. Tan and J. Pearl. Qualitative decision theory. In Proceeding of the 12th National Conference on Artificial Intelligence, AAAI94, pages 928933. MIT Press, Cambridge, 1994.

[296] A. Taylor. Mathematics and Politics: Strategy, Voting, Power, and Proof. Springer Verlag, Berlin, 1995. 
[297] F.W. Taylor. The principles of Scientific Management. Harper and Row, New York, 1911.

[298] E. Trist and H. Murray. The Social engagement of social science: a Tavistock anthology, vol. 2. University of Pennsylvania Press, Philadelphia, 1993.

[299] C. Tsang. Foundations of Constraint Satisfaction. Academic Press, New York, 1993.

[300] A. Tsoukiàs. A first-order, four valued, weakly paraconsistent logic and its relation to rough sets semantics. Foundations of Computing and Decision Sciences, 12:85-108, 2002.

[301] A. Tsoukiàs, P. Perny, and Ph. Vincke. From concordance/discordance to the modelling of positive and negative reasons in decision aiding. In D. Bouyssou, E. Jacquet-Lagrèze, P. Perny, R. Slowinski, D. Vanderpooten, and Ph. Vincke, editors, Aiding Decisions with Multiple Criteria: Essays in Honour of Bernard Roy, pages 147-174. Kluwer Academic, Dordrecht, 2002.

[302] A. Tsoukiàs and Ph. Vincke. A new axiomatic foundation of partial comparability. Theory and Decision, 39:79-114, 1995.

[303] A. Turing. On computable numbers, with an application to the entscheidungsproblem. Proceedings of the London Mathematical Society, 42:230-265, 1937.

[304] A. Turing. Computing machinery and intelligence. Mind, 49:433-460, 1950.

[305] A. Tversky. Additivity, utility and subjective probability. Journal of Mathematical Psychology, 4:175-201, 1967.

[306] A. Tversky. Intransitivity of preferences. Psychological Review, 76:31-48, 1969.

[307] A. Tversky. Elimination by aspects: A theory of choice. Psychological Review, 79:281-299, 1972.

[308] A. Tversky. Features of similarity. Psychological Review, 84:327-352, 1977.

[309] A. Tversky. On the elicitation of preferences: Descriptive and prescriptive considerations. In D. Bell, R.L. Keeney, and H. Raiffa, editors, Conflicting objectives in Decisions, pages 209-222. J. Wiley, New York, 1977. 
[310] A. Tversky and D. Kahneman. The framing of decisions and the psychology of choice. Science, 211:453-458, 1981.

[311] A. Tversky and I. Simonson. Context-dependent preferences. Management Science, 39:1179-1189, 1993.

[312] E.L. Ulungu and J. Teghem. Multi-objective combinatorial optimization: a survey. Journal of Multi-Criteria Decision Analysis, 3:83-104, 1994.

[313] S. Vajda. The theory of games and linear programming. J. Wiley, New York, 1956.

[314] P. Van Hentenryck. Constraint satisfaction in logic programing. MIT Press, Cambridge, 1989.

[315] D. Vanderpooten. Modelling in decision aiding. In D. Bouyssou, E. JacquetLagrèze, P. Perny, R. Slowinski, D. Vanderpooten, and Ph. Vincke, editors, Aiding Decisions with Multiple Criteria: Essays in Honour of Bernard Roy, pages 195-210. Kluwer Academic, Dordrecht, 2002.

[316] D. Vanderpooten and Ph. Vincke. Description and analysis of some representative interactive multicriteria procedures. Mathematical and Computer Modelling, 12:1221-1238, 1989.

[317] Ph. Vincke. Aggregation of preferences: a review. European Journal of Operational Research, 9:17-22, 1982.

[318] Ph. Vincke. Arrow's theorem is not a surprising result. European Journal of Operational Research, 10:22-25, 1982.

[319] Ph. Vincke. Multicriteria Decision-Aid. J. Wiley, New York, 1992.

[320] J. von Neumann and O. Morgenstern. Theory of games and economic behavior. Princeton University Press, Princeton, 1944. Second edition in 1947, third in 1954.

[321] D. von Winterfeldt and W. Edwards. Decision Analysis and Behavorial Research. Cambridge University Press, Cambridge, 1986.

[322] G.H von Wright. The logic of preference. Edinburgh University Press, Edinburgh, 1963.

[323] G.H von Wright. The logic of preference reconsidered. Theory and Decision, 3:140-169, 1972. 
[324] P.P. Wakker. Additive representations of preferences - A new foundation of decision analysis. Kluwer Academic, Dordrecht, 1989.

[325] P.P. Wakker and A. Tversky. An axiomatization of cumulative prospect theory. Journal of Risk and Uncertainty, 7:147-176, 1993.

[326] P.P. Wakker and H. Zank. A simple preference-foundation of cumulative prospect theory with power utility. European Economic Review, 46:12531271, 2002.

[327] P. Watzlawick. The situation is hopeless, but not serious: (the pursuit of unhappiness). Norton, New York, 1983.

[328] P. Watzlawick, J.H. Beavin, and D.D. Jackson. Pragmatics of Human Communication. W.W. Norton, New York, 1967.

[329] P. Watzlawick, J.H. Weakland, and R. Fisch. Change; principles of problem formation and problem resolution. Norton, New York, 1974.

[330] E.U. Weber and O. Çoskunoğlu. Descriptive and prescriptive models of decision making: implications for the development of decision aid. IEEE Transactions on Systems, Mans and Cybernetics, 20:310-317, 1990.

[331] M. Weber. Wirtschaft und Gesellschaft. Mohr, Tubingen, 1922.

[332] M.P. Wellman and J. Doyle. Preferential semantics for goals. In Proceedings of the 9th National Conference on Artificial Intelligence, AAAI91, pages 698-703. AAAI Press, Menlo Park, 1991.

[333] J.A Weymark. Arrow's theorem with social quasi-orderings. Public Choice, 42:235-246, 1984.

[334] D.J. White and K. Bowen. The role and effectiveness of theories of decision in practice. Hodder and Stoughton, London, 1975.

[335] N. Wiener. Cybernetics. MIT Press, Cambridge, 1948.

[336] H.P. Williams. Model building in mathematical programming. J. Wiley, New York, 1990. third edition.

[337] L.A. Zadeh. Fuzzy sets. Information Control, 8:338-353, 1965.

[338] L.A. Zadeh. Fuzzy sets as a basis for theory of possibility. Fuzzy Sets and Systems, 1:3-28, 1978. 
[339] M. Zeleny. Compromise programming. In J. L. Cochrane and M. Zeleny, editors, Multiple Criteria Decision Making, pages 262-301. University of South Carolina Press, Columbia, SC, 1973. 